\title{
PATRIMONIO URBANO Y HERÁLDICA GENTILICIA DE LA HIDALGUÍA ALBACETENSE A TRAVÉS DE LOS CANTOS BARNUEVO Y LOS CARRASCO
}

\section{THE URBAN HERITAGE AND GENTILE HERALDRY OF THE AL- BACETE NOBILITY THROUGH THE CANTOS BARNUEVO AND LOS CARRASCO}

\author{
ELVIRA VALERo DE LA Rosa \\ Archivo Histórico Provincial \\ Albacete, JCCM, España \\ evalero@jccm.es
}

Cómo citar este artículo: Valero de la Rosa, E. (2020). Patrimonio urbano y heráldica gentilicia de la hidalguía albacetense a través de los Cantos Barnuevo y los Carrasco. Al-Basit (65), 5-40. http://doi.org/10.37927/al-basit.65_1

Recibido/Received: 16-01-2020

Aceptado/Accepted: 31-10-2020

RESUMEN: Reconstruir la historia de la posada del Rosario, antes de que fuera hospedaje, nos ha llevado a sus auténticos dueños: Los Pando Barnuevo, familia de hidalgos en cuya unión confluyen varias ramas de la más rancia hidalguía local: los Cantos, de Albacete y los Barnuevo o Barrionuevo de Chinchilla ${ }^{1}$. A través de los protocolos notariales hemos descubierto otras casas principales de la familia como la conocida con el nombre "del marqués de Montortal" que desapareció a principios del siglo XX y que presentaba un

${ }^{1}$ El apellido Barnuevo o Barrionuevo lo usan de forma indistinta, así lo hemos respetado.
ABSTRACT: Reconstructing the history of El Rosario inn, before it was lodging, has brought us to its true owners: The Pando Barnuevo family, nobles in whose union converge several branches of the most ancient local nobility: Los Cantos, from Albacete, and Barnuevo or Barrionuevo from Chinchilla. Investigating notarial protocols we have discovered other main houses of the family such as the one known as the Marquis of Montortal house that disappeared at the beginning of the 20th century and that presented a beautiful quartered shield, whose fields have been known almost entirely thanks to the military orders archives. 
hermoso escudo cuartelado, cuyos campos nos han sido conocidos casi en su totalidad gracias a los expedientes de órdenes militares.

La restauración de la posada en los años 90 del siglo pasado y la colocación en un lateral de la portada de la "casa de los picos", antigua casa de los condes de Villaleal en la calle Gaona, nos ha llevado a otro linaje albacetense: el de los Carrasco. Gracias a la documentación administrativa, notarial y a la heráldica hemos podido identificar linajes y datar con aproximada precisión estos inmuebles.

PALABRAS CLAVE: heráldica, hidalguía, patrimonio artístico, Cantos, Pando, Barnuevo, Carrasco.
The inn restoration in the $90 \mathrm{~s}$ of the last century and the placement on one side of the cover of the "house of the peaks", former house of Villaleal counts on Gaona street, has taken us to another Albacete lineage: the Carrasco. Thanks to the documentation we have found and the heraldry we have been able to identify lineages and date these houses.

KEY WORDS: heraldry, coats of arms, nobility, artistic heritage, main houses. Albacete Cantos, Pando, Barnuevo, Carrasco, Núñez Robles, Villores, Montortal.

\section{INTRODUCCIÓN}

Cuesta imaginar en una ciudad como Albacete, donde casi todo vestigio antiguo ha desaparecido de sus calles, que existieron" casas principales" -diferenciadas de las "casas de morada" por su entidad, lugar de ubicación y monumentalidad-, solariegas quizá, con patios porticados, yeserías, artesonados, fachadas de piedra y escudos heráldicos que mostraban la calidad de sus moradores. Conocemos gracias a las fotografías de principios de siglo XX algunas de ellas, casi todas engullidas por el desarrollo urbano. A nuestros días sólo han llegado dos: la conocida como "posada del Rosario" y la denominada casa "Perona", nombre incorrecto, que responde a uno de sus últimos dueños, pero no a quien la erigió en el siglo XVIII.

La posada del Rosario es un edificio único, representativo de una tradicional arquitectura de casa hidalga del primer tercio del siglo XVI (García-Saúco, 2006, p. 61)². Es el más antiguo de los inmuebles civiles

${ }^{2}$ Según Bartolomé Beltrán, Consejero de Bellas Artes provincial, en un informe 


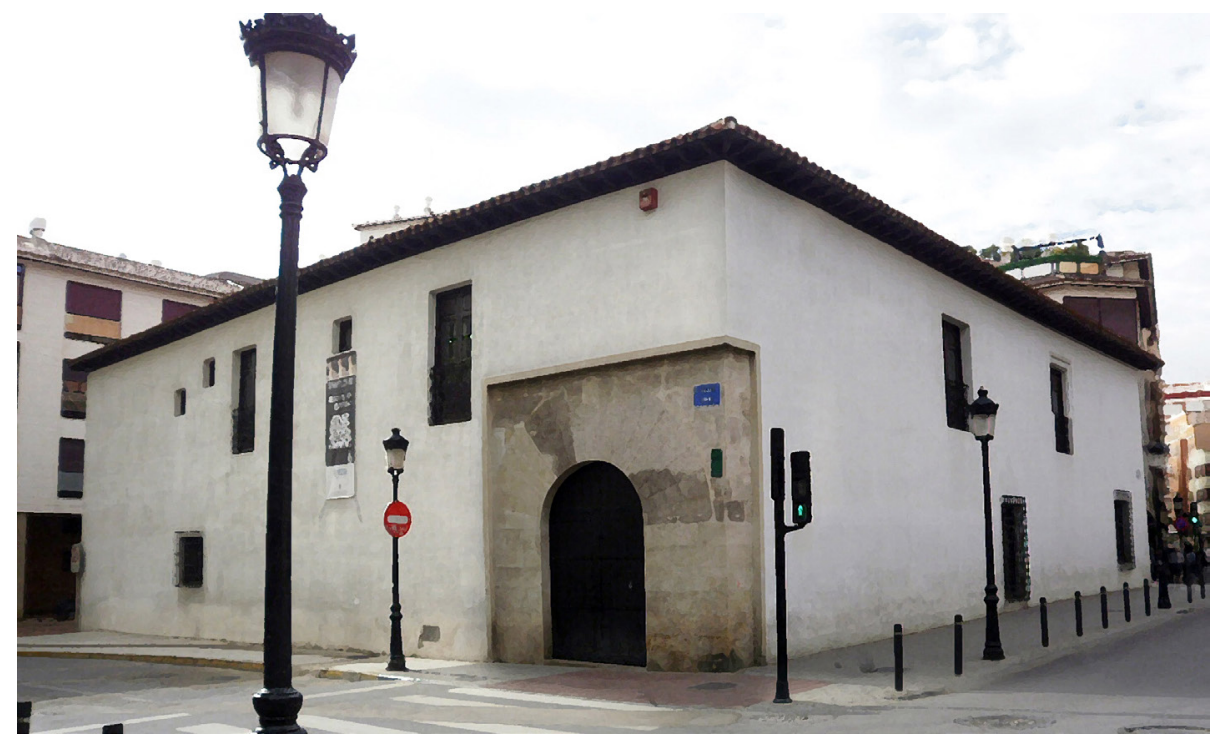

Figura 1. Puerta de acceso con arco de medio punto y anchas dovelas a la posada del Rosario en la calle del Tinte. Fotografía: Manuel López Collado.

que se conserva en Albacete, y, además, ahora podemos afirmar que perteneció a uno de los linajes más destacados de la hidalguía local: el de los Cantos Barnuevo. La vinculación de la propiedad a un mayorazgo y su transmisión a los herederos, los Pando Barnuevo, condicionaron su habitabilidad y su cambio de función cuando, ya disminuida la familia y reducidos al mínimo los sucesores, se transformó en posada. Gracias a esa adaptación ha llegado a nuestros días, siendo, por otra parte, la única de las antiguas posadas conservada (figura 1). La investigación sobre la familia propietaria en el siglo XVIII, los Pando o Pando Galiano de Cantos y Cañavate -como también gustan llamarse cuando reciben la herencia de su tío don Andrés de Cantos Barnuevo Cañavate en 1760-, nos ha llevado al mayorazgo heredado por este de su abuelo, don Andrés de Cantos, hijo del bachiller don Diego de Cantos, sucesor, en 1581, en el mayorazgo instituido por el capitán don Andrés de Cantos. Los bienes inmuebles nos han permitido descubrir otra propiedad personal: la desaparecida casa del marqués de Montortal, edificio que ostentaba los signos externos con los que la hidalguía mostraba el

de 1976, el edificio es "del siglo XVI, con ciertas influencias del XV. De estilo renacentista con reminiscencias platerescas, pero de estructura, sabor y ambiente auténticamente manchegos". AHPAB. Signatura 75.788, 4. 
prestigio de su linaje y la magnificencia de sus moradores: calidad de la construcción, ubicación, espacio, escudos y decoración que desvelaremos en este estudio con el fin de completar la información que ya poseíamos sobre estos inmuebles y que arrojan más luz sobre el patrimonio desaparecido de Albacete.

\section{EL MAYORAZGO DE LOS CANTOS BARNUEVO Y EL ORIGEN DE LA POSADA}

Según Alberto Mateos, la posada, en 1597, pertenecía a Manuel Barnuevo y Pando, pero el dato es anacrónico (1983, p. 204); ello, por los motivos siguientes: Pando no es un apellido oriundo de Albacete, aparecerá en 1707 debido al matrimonio entre doña Ángela Josefa Galiano de Cantos Barnuevo, natural de la villa, y don Manuel Pando y de los Cobos Sabiote y Domínguez de Zanoguera, natural de Madrid, hidalgo y caballero del hábito de Calatrava ${ }^{3}$. Ambos serán los padres de don Fernando, presbítero de la iglesia de San Juan, y de don Francisco Javier de Pando y Galiano, procurador general de la villa de Albacete, además de regidor y alguacil mayor perpetuo en Chinchilla, donde se casará con doña Ana María Barnuevo y Robles, aunque vivirán en Albacete según consta en el padrón de vecindades de $1761^{4}$. El matrimonio tuvo dos hijos, Ángela y Manuel Pando y Barnuevo, bautizado el 4 de julio de 1751. El expediente de ingreso de este en el Seminario de Nobles de Madrid, en 1764, nos ha proporcionado muchos datos genealógicos ya que se debía probar el linaje como verdadero patrimonio personal para ingresar en esta institución educativa. La familia de Manuel Pando Barnuevo procedía de hidalgos notorios de sangre -la calidad más alta entre ellos, por ser heredada de los antepasados-, "los Pandos y los Cantos, y en Chinchilla, los Barrionuevo y Núñez Robles"5. Manuel fue quien convirtió la casa heredada de su padre, don Francisco Javier de

\footnotetext{
${ }^{3}$ Datos que constan en el expediente de ingreso en la orden de Calatrava de don Manuel Pando de los Cobos, alguacil mayor jubilado del Santo Oficio de la Inquisición de Cuenca, año 1700, AHN OM-CABALLEROS_CALATRAVA, Exp.1944. La fecha de la boda en http://Familysearch.org [consulta 16/11/2019].

${ }^{4}$ AHPAB. Signatura 566, expediente 19. Como hidalgo aparece exento de la contribución personal

${ }^{5}$ AHN. UNIVERSIDADES, 669, Exp.11. Los abuelos paterno y materno fueron caballeros de Calatrava, tanto don Manuel Andrés Pando de los Cobos como don Salvador Barnuevo Abad de Villegas y Aro.
} 
Pando, en posada. La primera mención la hemos hallado en los protocolos notariales de 1797, fecha en la que, como propietario, denunció a Santos Corominas, el huésped que la regía desde 1795, por pretender abandonar el negocio antes de la fecha que el uso y la costumbre tenían convenidas, que eran Navidad o San Juan ${ }^{6}$. Quizá ya se viniera utilizando con este fin desde unos años atrás, pero desde luego debió ser con posterioridad a 1761, fecha de defunción de su tío don Fernando de Pando quien residía en ella.

\subsection{Genealogía de los Cantos Barnuevo}

Retomemos la genealogía de los abuelos paternos de don Manuel para alcanzar la línea albacetense -que es la que nos interesa- en la persona de doña Ángela Josefa Galiano de Cantos Barnuevo. Ángela era hija de Francisco Galiano Espuche, de Almansa, y de Catalina Antonia de Cantos Barrionuevo, de Albacete. Catalina, a su vez, era hija de Andrés de Cantos Barrionuevo del Cañavate, que había nacido en 1625, y de Úrsula Ochoa y Montañés y Guerrero, de Yeste. Andrés era hijo de Andrés de Cantos Barrionuevo, nacido en 1586 y de Ana Gascón Soriano. A su vez, Andrés era hijo de Diego de Cantos, nacido en 1553 y de María de Cañavate, casados el 4 de noviembre de $1579^{7}$. Este Diego de Cantos, bachiller, fue designado en 1581 por su tío de primo hermano el capitán don Andrés de Cantos, que murió sin descendencia, como continuador del mayorazgo. Diego era familiar por partida doble. Tanto su padre, Martín de Cantos, como su madre, Francisca Jiménez, eran primos hermanos del capitán. Martín era hijo de Martín de Cantos y Elvira Alonso ${ }^{8}$. A su vez, Martín era hijo de Martín de Cantos Sánchez

\footnotetext{
${ }^{6}$ AHPAB. Signatura 18.654, 32.

${ }^{7}$ Llama la atención en la partida de matrimonio los nombres de padrinos y testigos por pertenecer a la élite local. Juan de Alcañavate Soriano y doña Isabel de Cantos, su mujer. Testigos, Juan Granero de Heredia, clérigo, el capitán Andrés de Cantos y Alonso de Cantos, regidor. Http://Familysearch.org [consulta 16/11/2019].

${ }^{8}$ ARCHGR. 1545, expediente de hidalguía del bachiller Francisco de Cantos, hijo de Martín Sánchez de Cantos, más los nietos y bisnietos de aquel donde se establece la genealogía más remota. Incluye el privilegio de hidalguía otorgado por los RR CC en 1488. Recuperado en: https://www.familysearch.org/ark:/61903/3:1:3Q9M-CS2Z-J3P8-C?i=129\&cat=565576. Y carta ejecutoria https://www. familysearch.org/ark:/61903/3:1:3Q9M-CS2Z-J3LT-W?i=202\&cat=565576 [consulta 19/01/2020]. 1537-39. Curatela a favor del bachiller Francisco de Cantos sobre los hijos del difunto Martín de Cantos, su hermano. Probanza de hidalguía. Recuperado en: https://www.familysearch.org/ark:/61903/3:1:3Q9M-CS2D-PHBM-W?i=939\&cat=565576
} 


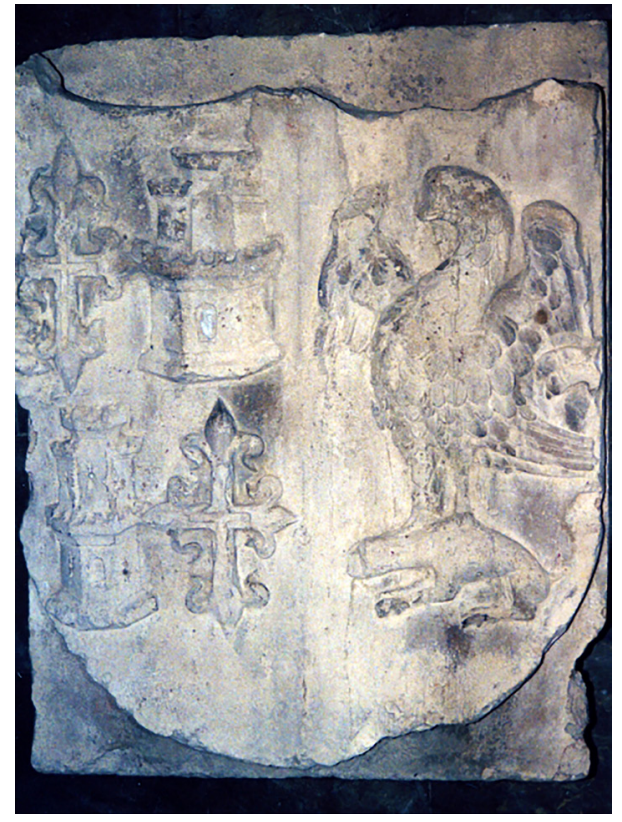

Figura 2. Escudo partido. Primer cuartel, Barnuevo. Segundo, Cantos. Escudo utilizado por la familia Cantos Barnuevo de Albacete que se conserva en el Museo Provincial. Procede del convento de Justinianas. Fondo IEA.

Fotografía: Antonio Moreno. y Juana Sánchez. Se entroncaba a través de este con Martín Sánchez de Cantos (o del Villar de Cantos, como lo nombran varios documentos ${ }^{9}$ ), el viejo, casado con Juana García de Barnuevo, los que iniciaron el linaje de $\mathrm{Al}$ bacete en el siglo $\mathrm{XV}$, a quienes los Reyes Católicos, a su paso por la villa, honraron con la concesión de un título de hidalguía en atención a los servicios proporcionados a los monarcas en la guerra contra el marqués de Villena (Santamaría, 2002, pp. 75-91). Podemos considerar que el apellido toponímico "Villar de Cantos" se simplificó en "Cantos", surgiendo un nuevo linaje con solar en Albacete. De ahí que las armas que presenta -un águila empietada de un conejo- sean distintas de las de otros "Cantos" con otros orígenes, según observamos en el Nobiliario de Julio de Atienza (1959, p. 19). La fusión con los Barnuevo se contempla en el escudo usado por sus descendientes como el que se exhibía en la casa del capitán don Rodrigo de Cantos en el Altozano antes de que se convirtiera en convento $^{10}$.

\footnotetext{
${ }^{9}$ Año 1451. Poder a Martín Sánchez del Villar de Cantos para representar al concejo de Albacete ante el marqués de Villena. AHPAB. Signatura, 552, 6. Año 1462. Sentencia a favor de Martín Sánchez del Villar de Cantos sobre la recaudación del servicio y montazgo. AHPAB. Signatura 552, 62.

${ }^{10}$ AHN. OM-SAN_JUAN_DE_JERUSALEN, Exp. 23666. Año 1667, expedientes de pruebas para la concesión del título de caballero de la orden de San Juan de Jerusalén a los hermanos Francisco de Zúñiga y Cantos, natural de la villa de San Clemente, José de Zúñiga, natural de Madrid, Luis de Zúñiga y Rodrigo de Zúñiga, ambos naturales de Víllora. La información practicada por los comisarios incluye la visita al convento de monjas de la Concepción para ver las armas que están en la pared de fuera: "un escudo con un águila y a los pies un conejo, que son las armas que
} 


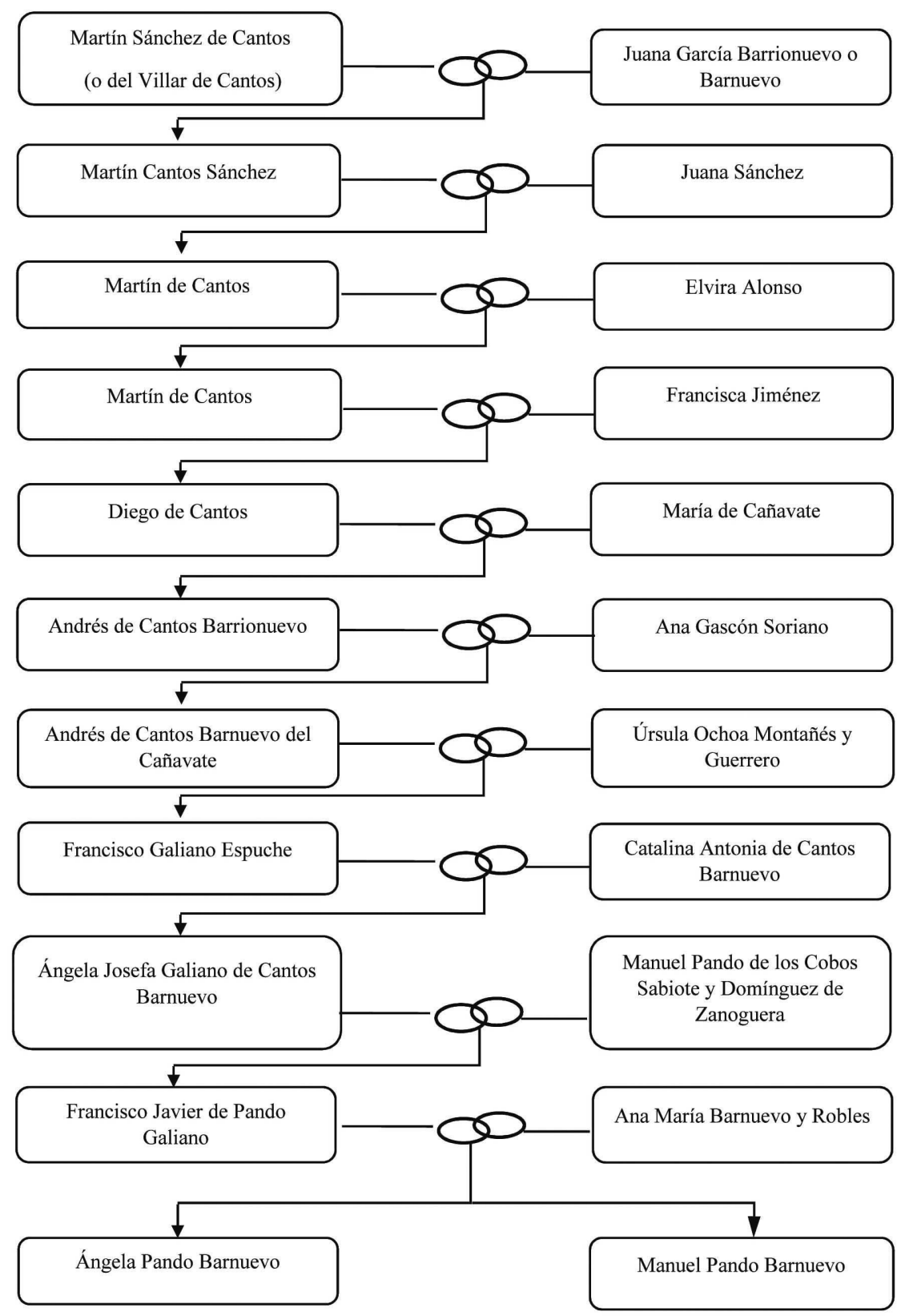

Figura 3. Árbol genealógico de don Manuel Pando Barnuevo. Elaboración propia.

usan los Cantos [...] Esta casa antes de convento era de sus abuelos", según declaración de don Francisco de Zúñiga y Cantos. Incluye el dibujo en color del escudo. 
Por tanto, descendía don Manuel de uno de los linajes con más solera y antigüedad de Albacete, los Cantos-Barnuevo (figura 3). En él recayeron diversos vínculos y mayorazgos que le proporcionaban una elevada situación económica desde su infancia. Así lo adelantaba su madre, Ana María Barnuevo, al testar en abril de 1761, disponiendo una cláusula para equilibrar o administrar la riqueza de sus hijos y herederos universales, Manuel y Ángela, concediendo el quinto de sus bienes a su esposo, si quisiere disponer de ellos ${ }^{11}$.

Uno de los mayorazgos que recayeron en la familia procedía de don Andrés de Cantos Barnuevo Cañavate, hermano de su abuela. El 6 de julio de 1760, don Andrés otorgó poder para testar en su nombre a su sobrino don Francisco Javier de Pando Galiano de Cantos. El heredero universal sería su hermano mayor, el presbítero de la iglesia de San Juan, don Fernando de Pando Galiano de Cantos (Gómez, 2007, p. $113)^{12}$. A don Francisco Javier le legó el heredamiento de Casa Nueva -que fue propio de don Diego Tomás de Cantos y doña Isabel Royo y Escobar, abuelos maternos de don Andrés- y otra haza de tierra libre de vínculo y mayorazgo en el paraje del Acequión ${ }^{13}$. Según el testamento, los seis o siete vínculos y mayorazgos procedían de don Andrés de Cantos Barnuevo, su padre, quien igualmente los heredó de su abuelo, el señor don Andrés de Cantos Barnuevo.

Algunos de estos mayorazgos, tenían algunas cláusulas de incompatibilidad, bien con el estado eclesiástico (al desaparecer la descendencia se extinguía el linaje), bien con otros mayorazgos como el de Orna que ya pertenecía a don Fernando de Pando. Por este motivo recaerían algunas posesiones en el segundogénito, don Francisco Javier. Entre ellas una "casa de morada principal", cuya ubicación se describe así: "que está en la población de esta villa y hace esquina a la calle que desde la calle Mayor va al Vía Crucis y ermita de Nuestra señora del Rosario y Santo Sepulcro, quedando la casa a la mano izquierda y a la que desde la plaza pública y calle que llaman de la Caba se lleva a la que llaman del Tinte, plazuela y ermita del señor San José, contigua esta casa a una huerta para hortaliza propia de estos mayorazgos que está a la par-

${ }^{11}$ AHPAB. Signatura 3.305.

${ }^{12}$ AHPAB. Signatura 1.024. 4ํㅜ , pp. 28-35v. Andrés de Cantos falleció el 14 de julio de 1670.

${ }^{13} \mathrm{Al}$ margen del testamento el escribano anota que quedó vinculada esta haza del Acequión a don Francisco Javier en lugar de los bienes vinculados en la villa de Almansa por don Francisco Galiano y don Pedro Carrasco. AHPAB. Signatura 1.024, 4o, p. 32v. 
te del camino del Vía Crucis y es muy grande y no confina con otro edificio de casa alguna" (figura 4). Como podemos comprobar está describiendo la ubicación del inmueble que hoy en día conocemos con el nombre de "posada del Rosario" -entonces casa particular- que arrendará por veinte ducados de vellón anuales a su hermano, don Fernan-

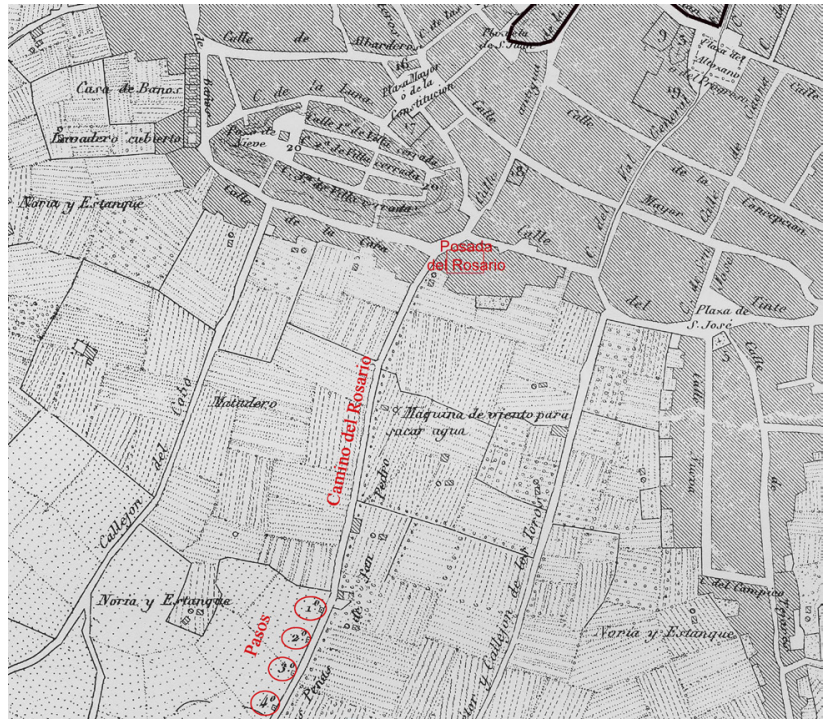

Figura 4. 1876. Detalle del plano de Albacete por Francisco Coello. Hemos señalado en rojo la posada del Rosario, el camino y los pasos. Se pueden observar las huertas y la falta de edificaciones en esa zona. En el camino aparecen numerados ordinalmente los pasos: $1^{\circ}, 2^{\circ}, 3^{\circ}, 4^{\circ} \ldots$ (BNE). do, ya que este no tiene otra casa "proporcionada para su habitación", mientras que don Francisco declaraba poseer una casa principal que "ha labrado por sí y está perfeccionándola al presente", refiriéndose a la casa que será conocida como "del marqués de Montortal" que analizaremos después ${ }^{14}$. Esta casa fue catalogada como de primera categoría y fue seleccionada para alojar al cortejo de la infanta María Luisa a su paso por Albacete en 1765, su situación en la placeta de San Juan, hoy plaza de la Constitución, le proporcionaba una ubicación y prestancia inmejorable ${ }^{15}$

Por el contrario, la casa localizada en el camino del Rosario se hallaba en el extrarradio del núcleo urbano, pero contaba con una ventaja importante como era la cercanía a la huerta y tierras de los Cantos. Lo comprobamos en el testamento que doña María de Vergara, viuda de Martín de Cantos Barnuevo, realizó en 1656, donde enumera entre sus bienes un cercado de oliva y vides en el camino del Rosario ${ }^{16}$. En

\footnotetext{
${ }^{14}$ AHPAB. Signatura 1.024, 4으, pp. 40-42v.

${ }^{15}$ AHPAB. Signatura 322. 1765, expediente de tránsito de la infanta María Luisa por Albacete.

${ }^{16}$ AHPAB. Signatura 999.
} 
1528 nos ha aparecido, en ese paraje, Martín de Cantos, dueño de un cebadal que lindaba con el camino que va a Señora Santana (nombre indicativo de que en esa fecha no se había erigido la ermita del Rosario ${ }^{17}$. Referencias a la casa de Martín de Cantos en aquel entorno nos las proporcionan muchos documentos: al tratar del itinerario de las calles empedradas, al señalar el peligro de las puertas por las epidemias de peste, al elaborar el padrón de 1571, al erradicar la tenería por los malos olores...

\section{LOS BIENES RÚSTICOS Y URBANOS DE LOS PANDO BARNUEVO EN ALBACETE}

El 9 de abril de 1761 don Fernando José Pando Galiano, presbítero de la iglesia de San Juan de Albacete, primogénito de don Manuel Pando de los Cobos Soler y Zanoguera, realizó testamento dejando como sucesor de varios vínculos y mayorazgos en las ciudades de Murcia y Orihuela, huertas y campos, a su hermano don Francisco. De esta forma se sumaba a su fortuna un nuevo mayorazgo, el que fundó en Orihuela Andrés Soler Rocaful, que era incompatible con otro que ya poseía, el que fundó en Valencia don Manuel Zanoguera y que traspasará a su hijo don Manuel que por aquella época tenía diez años ${ }^{18}$.

Las propiedades de don Manuel en Albacete figuran en una declaración realizada en 1800 para la imposición de la contribución territorial. Así, de su puño y letra enumera su hacienda en la villa que se compone de cuatro mil fanegas de tierra de secano en seis heredades, que las cultivan veinte pares de mulas a rento por un quinquenio que producen cuarenta ducados por par. Dos pares de mulas que no le producen nada. Una posada que le da diez reales por día. Un majuelo arrendado a fruto sano en 1.400 reales. Una casa arrendada en cuarenta ducados. Y otra casa en diez ducados ${ }^{19}$. Sin embargo, no

\footnotetext{
${ }^{17}$ El arrendamiento del cebadal en AHPAB 552, 4. La ermita del Rosario se encontraba a unos $1.400 \mathrm{~m}$ de la calle de la Caba (Mateos, 1983: 89). Antes de llegar a ella el caminante se encontraba con los llamados "pasos del Vía Crucis", por lo que este camino también fue conocido con el nombre de "Los Pasos" o del "Vía Crucis". El plano de Francisco Coello, de 1876 (figura 4), y una fotografía de principios del siglo XX, publicada en la obra de Alberto Mateos, Del Albacete Antiguo, nos muestran la ubicación y la forma de aquellos pequeños oratorios.

${ }^{18}$ AHPAB. Signatura 3.305. y 1.024, año 1758 poder sobre vínculos y mayorazgos en Valencia.

${ }^{19}$ AHPAB. Signatura 566, 18.
} 
están aquí todas sus fincas. En 1787 suscribió un censo enfitéutico con don Francisco Velasco y Valcárcel, vecino de Hellín (ambos caballeros fijosdalgos notorios de sangre) propietario de los vínculos que fundaron Pedro de Cantos y su mujer Juana Gómez y que fue de Antón de Cantos, adquiriendo tres casas en la calle Botica, Castañeda y Pelota, todas antiguas, la última arruinada ${ }^{20}$.

Don Manuel Pando murió sin descendencia, heredando sus bienes, vínculos y mayorazgos su sobrino, don Ramón Barnuevo y Pando (1787-1855), hijo de su hermana Ángela, casada con otro hidalgo chinchillano, Sancho Barnuevo y Abat ${ }^{21}$. Entre sus títulos y cargos figuran los de caballero maestrante de la Real de Valencia, hidalgo y regidor perpetuo de Chinchilla ${ }^{22}$.

Según el padrón de propiedades de 1814, don Ramón poseía las heredades de Acequión, Casa Grande, Albaydel, Casa Nueva (de Pando), la Torrecica, Miraflores, huerta de la Dehesa, la Culebrina, haza Cebadal, haza de Las Paletas, y otra suerte llamada del Rosario. Las casas son: la principal, en el callejón de Las Cartas, que no gana alquiler. Dos en la calle San Antón, otra en la calle del Cornejo y otra junto a la posada. A todo ello hay que añadir viñas y censos ${ }^{23}$. En 1849 se le contabilizan 8 carros, 36 caballerías mayores, 4 menores y 20 cerriles y de cría.

Con respecto a las propiedades urbanas, observamos diferencias en las declaraciones de distintos años. Así, en 1812, en el padrón de la contribución aparece con siete casas, la principal en la calle Cartas, otra en Concepción, dos en San Antón, una en Cornejo, otra en Zapateros, la posada y otra casa en la calle Caba. En 1818 se le contabilizan ocho inmuebles. En sucesivos padrones vemos otras, una junto a la posada y otra en la calle del juego de la Pelota (Pablo Medina actual) y la última

\footnotetext{
${ }^{20}$ AHPAB. Signatura 1.031, libro 5ㅇ․

${ }^{21}$ Sancho era hijo de Sancho Ramiro Barnuevo y Núñez-Robles, natural de Chinchilla, señor de Almagra, del Consejo de Castilla y Caballero de la Orden de Calatrava desde 1737, el cual casó el 11 de febrero de 1759 con Felipa Fernanda Abat y Ortega. AHN. O0. MM. EXPEDIENTILLOS, N.12008. Registros parroquiales en Http://familysearch.org.

${ }^{22}$ Listado de los caballeros maestrantes en:

http://bibliotecavirtual.malaga.es/i18n/catalogo_imagenes/grupo.cmd?path=1160725. [consulta 10/11/2019]. Regidor perpetuo y alguacil mayor en funciones de corregidor de Chinchilla en las actas de 1833. AHPAB. Signatura 4.490, 1. ${ }^{23}$ AHPAB. Signatura 295. Casa Nueva de Pando, propiedad de don Manuel de Pando, aparece con casa abierta en 1800 (AHPAB. Signatura 566, 18). Declaraciones de propietarios para la contribución.
} 
en el campo ${ }^{24}$. La de mayor valor es la de la calle de las Cartas, que es su residencia habitual en Albacete, "casa abierta", es decir, "habitada", según el padrón de $1849^{25}$. Pero cuando la Administración de Hacienda se hace cargo del catastro de rústica y urbana los datos serán más fidedignos consignándose a don Ramón Barnuevo en 1850 once inmuebles, el de la calle Cartas, ahora llamada del Correo, es el segundo en valor, tras la posada del Rosario ${ }^{26}$.

Don Ramón se mantuvo soltero y no tuvo descendencia, por lo que al morir declaró continuador de sus vinculaciones a su sobrino Cecilio Núñez Robles y Barnuevo a quien legó la mitad de todos sus bienes que por ley le correspondían en todos los predios rústicos y urbanos en Albacete, La Gineta, Valencia y su huerta, más la labor del Villar con la casa grande, la del horno, la fragua, la que habita el cura, la de la monja y la posada vieja (la posada nueva del Villar es para otro sobrino, Fernando Núñez-Robles), las tierras de Hoya Gonzalo y la huerta de Balazote en las inmediaciones de esta ciudad ${ }^{27}$. Cecilio falleció pocos meses después de recibir la cuantiosa herencia de su tío, pasando la posada del Rosario a su hija María Dolores, que se casó con José Salvador La Figuera, marqués de Villores. El edificio fue vendido en 1912 a la familia Sánchez Rodríguez. En 1933 la compro Baldomero Sánchez Felipe y en 1945 la heredó Evigio González Navarro ${ }^{28}$.

\subsection{La casa principal de don Ramón Pando Barnuevo}

Si la posada del Rosario se salvó de la ruina gracias a su conversión en hospedaje, no corrió la misma suerte la casa principal de los Pando, situada al principio de la calle del Rosario, que fue demolida antes del año 1943 pues en gran parte de su solar se construyó la Delegación de Hacienda y otra porción sirvió para la apertura de la calle

\footnotetext{
${ }^{24}$ AHPAB, Signatura 204. En 1812, en el padrón de la contribución aparece con siete casas, la principal en la calle Cartas, otra en Concepción, dos en San Antón, una en Cornejo, otra en Zapateros, la posada y otra casa en la calle Caba (AHPAB 204, 1).

${ }^{25}$ AHPAB. Signatura 302, expedientes 2 y 4 . Por su hacienda es catalogado en el padrón como terrateniente.

${ }^{26}$ AHPAB. Signatura 65.705, 7. Incluye todos los bienes rústicos, urbanos y semovientes de don Ramón Barnuevo en Albacete.

${ }^{27}$ Partida de defunción en http://Familysearch.org. Protocolización del testamento cerrado que realizó en 1849. AHPAB Signatura 3.903, año 1855, protocolo n.음 54, p. 134.

${ }^{28}$ AHPAB. Registro fiscal de edificios y solares. Signatura 67.729.
} 


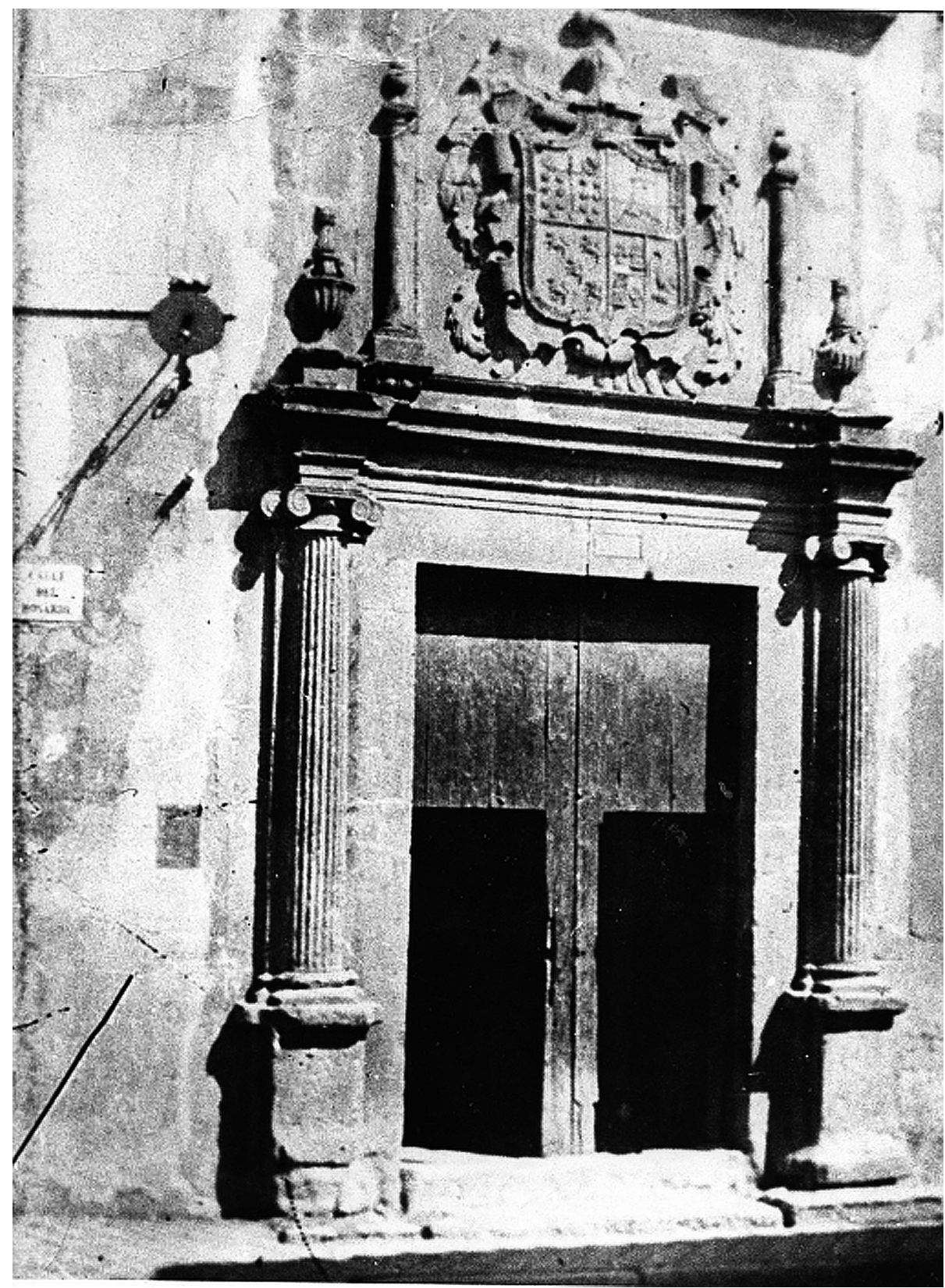

Figura 5. Casa desaparecida del marqués de Montortal en la calle del Rosario. A. Mateos. Del Albacete antiguo, p. 182, fotografía de Jaime Belda. 
Francisco Fontecha en los años 20. La fotografía más conocida es la aparecida en la obra de Alberto Mateos, Del Albacete Antiguo (1983, p. 168), tomada hacia 1910 según Luis Guillermo García-Saúco, quien la describe resaltando su semejanza a la fachada ya desaparecida del palacio del conde de Pinohermoso en el Altozano (figura 5). Destaca de ella la portada adintelada y las columnas corintias que ofrecen el dintel de apoyo al gran escudo rodeado de cueros y lambrequines (1982, p. 41. 1991, p. 191) ${ }^{29}$.

La casa aparece en un padrón de riqueza urbana del año 1818 como residencia de don Ramón Barnuevo en la denominada por aquel entonces como calle de las Cartas. La casa estaba valorada a efectos fiscales en 232.381 reales, con un producto de 2.200, mientras que la posada figuraba con valor de $116.000 \mathrm{y}$ un producto de 4.380 reales. El inmueble se componía de dos casas contiguas, una con el n. 9 duplicado y la siguiente con el número 11, con un total de $1.548 \mathrm{~m}^{2}$ de superficie ${ }^{30}$. Ese mismo año, según Sánchez Torres, el Ayuntamiento comenzó las gestiones para encontrar y habilitar local para alojar al regente de la Audiencia, y se designó la casa de don Ramón Barrionuevo, éste se negó, y se acordó ocuparla forzosamente, aunque no se llevó a efecto acto tan arbitrario (1916, p. 18).

La monumental fachada es denominada en todas las publicaciones en las que aparece como casa del marqués de Montortal, pero no se explica quién era el personaje ni su vinculación con Albacete $^{31}$. En el registro fiscal de edificios y solares para el año 1907 figuran las propiedades del citado marqués (sin especificar filiación) tan sólo su título nobiliario y su vecindad, Valencia ${ }^{32}$. La historia de la propiedad es la siguiente: a la muerte de don Ramón Barnuevo heredó su sobrino, Cecilio Núñez Robles y Barnuevo, diputado a Cortes en 1849, casado con María de la Encarnación Salvador y Frías, hija de don Joaquín María Salvador y Vidal, marqués de Villores, caballero de la Orden de Montesa, gentilhombre de cámara del rey y maestrante de Valencia

\footnotetext{
${ }^{29}$ GARCÍA-SAÚCO, Luis Guillermo: "Desarrollo urbanístico de Albacete" en Albacete en su Historia. Albacete: Ayuntamiento, 1991, p. 191.

${ }^{30}$ AHPAB, Signatura 67.723.

${ }^{31}$ Desde Alberto Mateos, Del Albacete antiguo, a Luis Guillermo García-Saúco: Albacete, 600 años. Albacete en su Historia y Arquitectura de la provincial de Albacete. ${ }^{32}$ AHPAB, Signatura 67.723. El marquesado de Montortal fue creado el 26 de octubre de 1790 para don José Antonio Tejedor y Judici de Acharte, Cerdán y Casaús, maestrante de Valencia, caballero de San Juan de Jerusalén.
} 


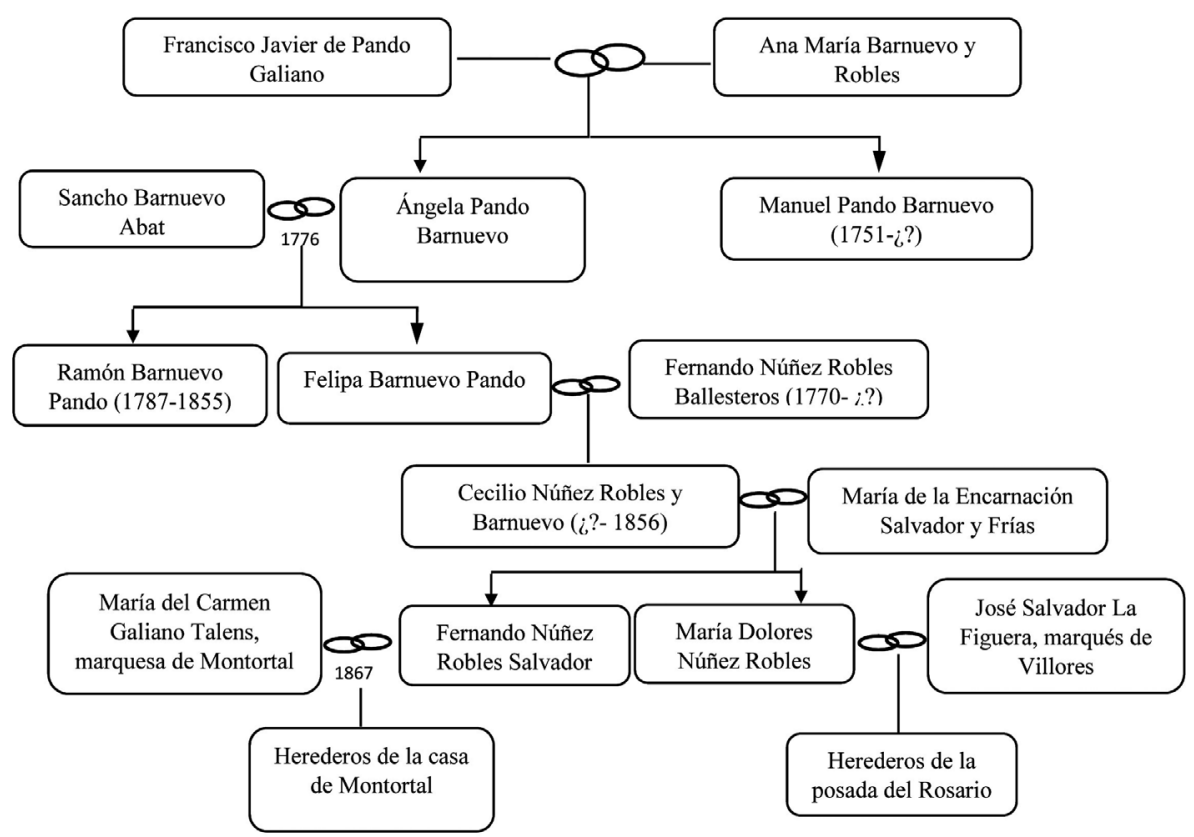

Figura 6. Árbol genealógico de don Ramón Barnuevo. Antepasados y sucesores. Sólo figuran los herederos de sus bienes. Elaboración propia.

y de doña María Josefa (Barroso) Frías y Jordá. Los abuelos paternos fueron don Fernando Núñez-Robles (1770) y Ballesteros y doña Felipa Barnuevo y Pando, ambos de Chinchilla. Los maternos procedían de Valencia y de San Roque en la provincia de Cádiz respectivamente. A su muerte, acaecida en 1856, le sucedieron en la herencia sus hijos: Fernando Núñez Robles Salvador (1842-1903) casado en 1867 con María del Carmen Galiano Talens (1839-1919), marquesa de Montortal. El título lo heredó de su padre Miguel Nicolás Galiano Tejedor, casado con María del Carmen Talens Ulloa. A Fernando le sucedió su hijo, llamado Fernando Núñez Robles Galiano, marqués de la Calzada y de Montortal 1882-1969, casado con María del Pilar Rodríguez de Valcárcel León, marquesa de Rosa, que fueron los últimos dueños del inmueble ${ }^{33}$.

${ }_{33}$ https://gw.geneanet.org/sanchiz?lang=en\&p=fernando\&n=nunez+robres+galiano. 


\subsection{Análisis del escudo de la casa principal}

El escudo de la casa no puede ser anterior al año 1707, ya que es en esa fecha cuando contraen matrimonio don Manuel Andrés de Pando de los Cobos y doña Ángela Josefa Galiano de Cantos Barnuevo, de Albace-

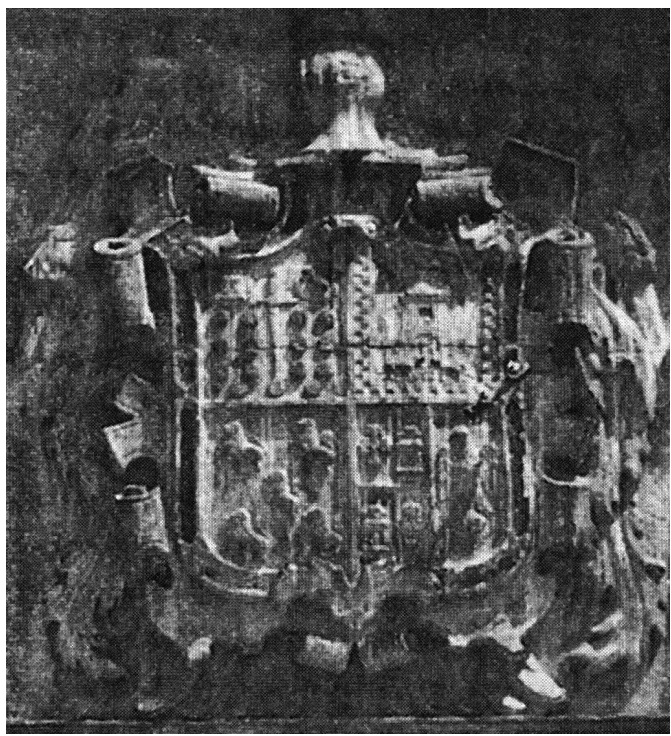

Figura 7. Detalle del escudo con los cuatro cuarteles. En el primero, pese a la falta de nitidez, se puede apreciar una espada abatida con siete roles a cada lado y uno en punta que debe pertenecer a los Pando te, cuyos linajes aparecen en el cuartelado en cruz, método idóneo para representar los cuatros costados de una ascendencia, pues permite colocar las armas de los cuatro abuelos y abuelas del titular del escudo (figura 7). Sabemos, además, que, en 1760, el hijo de ambos, don Francisco arrendaba la casa de la calle del Rosario, esquina a la del Tinte, a su hermano presbítero porque él ya poseía una casa principal que "ha labrado por sí y está perfeccionándola al presente". Por tanto, la casa se debió construir a mitad del siglo XVIII, si bien muestra una portada que recuerda a los palacios renacentistas, modelo arquitectónico de gran influencia que perduró hasta el siglo XVIII (González-Varas, 2018, p. 201).

Los expedientes para ingreso en las órdenes militares de varios familiares nos aportan los datos sobre genealogía y armas de cada rama $^{34}$. El primero es del año 1700 y corresponde a don Manuel Andrés Pando de los Cobos, nacido en 1678, pretendiente al hábito de Calatrava. El padre del interesado, don Fernando de Pando (1641), fue natural de Murcia, su madre, Mariana de los Cobos (1657), natural de Jumilla. El abuelo paterno, Simón de Pando, fue oriundo del valle de Trucios, "encartaciones de Vizcaya", y la abuela paterna, doña Angela

34 1700. Expediente de don Manuel Pando de los Cobos. Recuperado en: https://www.familysearch.org/ark:/61903/3:1:3Q9M-CS2T-BWD3-S?i=2133\&cat $=666660$ [consulta 20/07/2018]. 
Sabiote (1621), fue natural de Murcia. En el expediente no se describe el escudo, pero coinciden los tratados de heráldica en la procedencia de su primitivo solar vinculado con la parroquia de San Juan de Pando, lugar que pertenece al Ayuntamiento de Carranca y partido judicial de Valmaseda, en Vizcaya. Otras casas, dimanadas de la anterior, radicaron en el Valle de Trucios, del partido de Valmaseda, y en el lugar de San Miguel de Ahedo, del Ayuntamiento de Carranza. Valero de Bernabé señala la espada como propia de Pando en Castilla, así como las crucetas. Las panelas también figuran en el apellido Pando de las vascongadas de donde eran oriundos los del linaje asentado en Castilla $(2007,433)$.

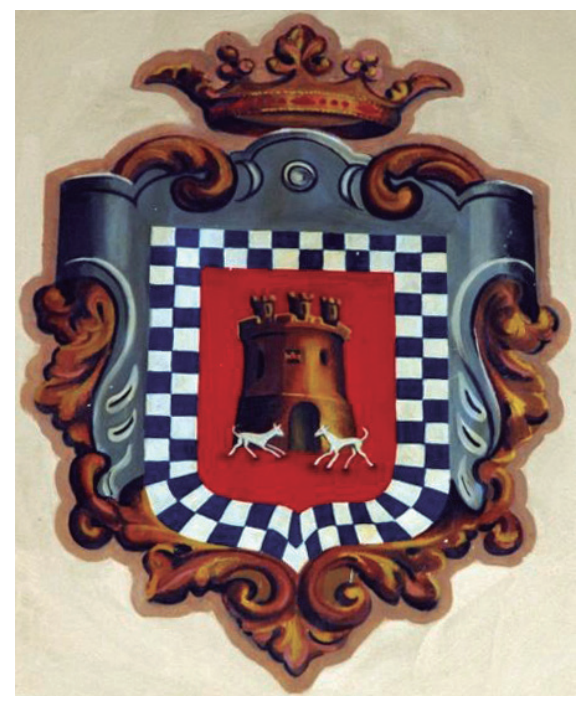

Figura 8. Escudo de los Galiano de Almansa. Imagen aportada por Alfonso Arráez.

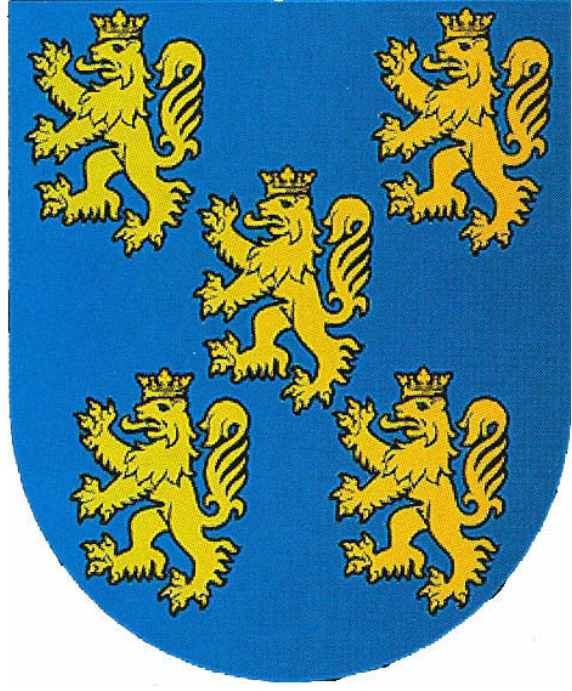

Figura 9. Escudo de los Cobos. Imagen extraída de Armorial de apellidos españoles. Ilustración de Jacques-A. Schnieper.

El segundo cuartel pertenece a los Galiano de Almansa (figura 8). Ángela Josefa Galiano de Cantos Barnuevo era hija de Francisco Galiano Spuche y de Catalina de Cantos Barnuevo, casados en 1690. Al no encontrar la descripción del escudo en el expediente he recurrido a las casas solariegas de su procedencia en Almansa, de las que me ha proporcionado unos datos muy interesantes el investigador local Alfonso Arráez quien nos comenta que sobre éstas únicamente se conserva la del mayorazgo de don Miguel, es decir la de la rama principal, situada 
en la calle Aragón y que pertenece en la actualidad a los marqueses de Montortal. Sobre los escudos heráldicos de la familia, se conservan dos ejemplos en la antigua iglesia del convento de Agustinas (hoy desacralizada), fundada en 1609 por los Galiano Pina, otra rama lateral. Consiste en una torre y dos perros sobre campo de gules, y bordura jaquelada.

El tercer cuartel pertenece a los abuelos maternos que fueron Francisco Pérez de los Cobos (caballero de la orden de Santiago), de Jumilla, y Concordia Domínguez de Zanoguera, natural de Valencia (1629) (figura 9). En las averiguaciones de la familia materna en Jumilla se reconocen las armas que los Pérez de los Cobos tienen en la capilla, la segunda al lado del evangelio que se llama capilla del Santo Cristo, cuyo escudo, colocado sobre la reja de dicha capilla, pertenece al apellido y familia de Pérez de los Cobos y se compone de cinco leones en campo azul y abraza el dicho escudo el hábito de Santiago y encima una coro$n^{35}$. El expediente ahonda en comprobaciones heráldicas, tanto en las casas de Hernando Sabiote, cuyo escudo partido en cuatro cuarterones está tan desgastado que no se aprecia- lo que demuestra la antigüedad del linaje-, como en la casa del mayorazgo, en la calle del Rico, donde vive el primo hermano del pretendiente, don Francisco Antonio Pérez de los Cobos. Sobre la portada grande de piedra en la puerta principal reconocieron el mismo escudo de cinco leones.

El último cuartel pertenece a los Cantos Barnuevo de Albacete (figura 10). La información sobre los Barnuevo es amplísima, ya que fue uno de los doce linajes troncales, de caballeros "fijosdalgo" notorios, que hubo en la ciudad de Soria. El primer documento escrito sobre ellos se remonta al año 909 en que Diego Álvarez de Barnuevo hizo donación de palacios y heredamientos al monasterio de San Millán. La rama troncal se extiende hasta Juan Barnuevo y Mendoza que en 1450 se estableció en Chinchilla en donde edificó su casa solar y casó con Juana García (Mogrobejo, 2003, pp. 171-184). En cuanto al origen de esta casa don Francisco Mosquera de Barnuevo en "la Numantina", editada en 1612, dice. "Los Barnuevo son muy buenos caballeros, hijosdalgo muy notorios, y fueron antiquísimos Numantinos, y llámanse de ese nombre por haber hecho nuevo Barrio de la nueva Numancia, que hoy se llama Soria". Describe las armas de esta forma: escudo cuartelado con castillo

${ }^{35} \mathrm{https}: / /$ www.familysearch.org/search/catalog/666660 [consulta 17/11/2019] 


\section{BARRIONVEV ${ }_{q}^{\circ}$}

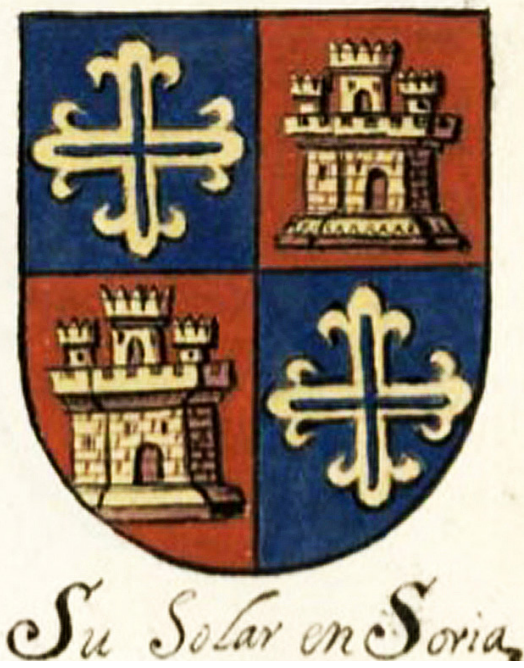

Figura 10. Escudo de los "Barrionuevos". Año 1650. Cárdenas, I.: Varios apellidos y armas legalmente sacados de un Nobiliario que para en el Archivo del Real Convento de S. Pablo de Córdoba. Biblioteca Nacional. Manuscrito

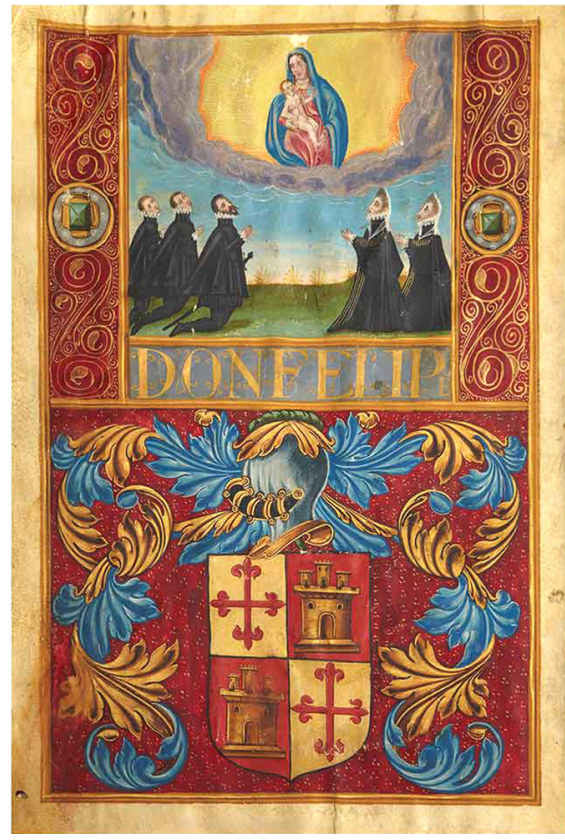

Figura 11. Ejecutoria de hidalguía a favor de Pedro, Clemente, Juan de Barnuevo, Rodrigo Pinar y Hernando Vázquez de Barnuevo, retratados en la parte superior, orando ante una imagen mariana. Año 1591. En la parte inferior aparece el escudo cuartelado con el orden invertido de castillos y cruces con respecto al original. El pleito se conserva en el Archivo de la Real Chancillería de Granada. Signatura 469-5. La imagen de la ejecutoria está tomada de https:// www.christies.com/

de oro en campo de sangre y cruz hueca de Calatrava de oro en campo azul, contrapuesto. Según la tradición, el escudo original era un castillo al que se sumó la cruz por concesión real tras una batalla contra los moros, ganada por un caballero de este linaje que la acometió y venció tras ver una premonitoria cruz en el cielo. (Barreda, 2011, p. 582). En este escudo de Albacete, el castillo ocupa los cuarteles segundo y tercero, tal y como aparece en la ejecutoria de hidalguía del año 1591, que reproducimos al margen, a favor de la rama chinchillana (figura 11). tán Andrés de Cantos en su testamento de 1581: 
Campo partido; a la siniestra, en campo dorado un águila caudal con un conejo en las uñas; y a la diestra, cuartelado, con una cruz blanca de Calatrava, en campo de azur, en el primero y cuarto, y un castillo de oro

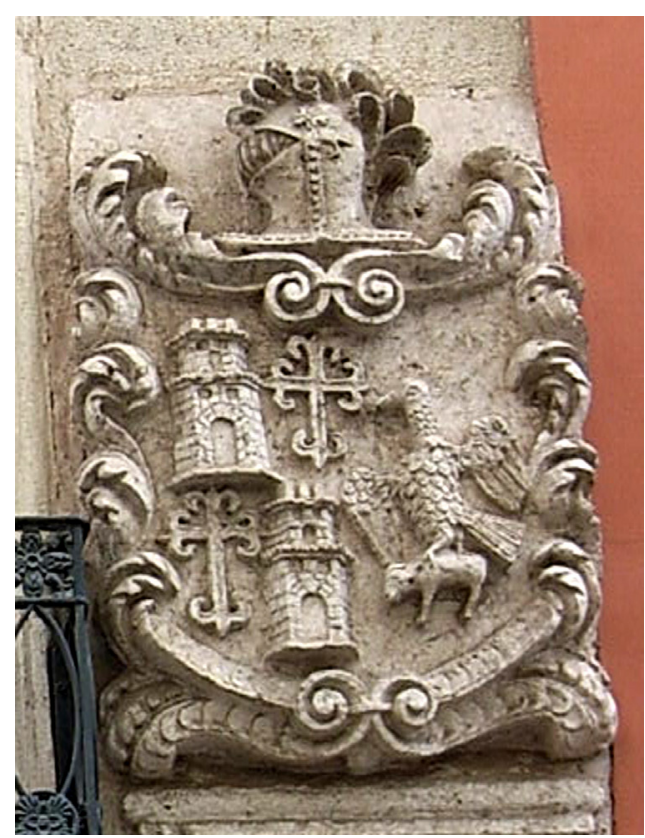

Figura 12. Escudo de los Cantos Barnuevo de Albacete en la fachada de la casa "Perona" en la calle de la Feria, propiedad en el siglo XVIII de Juan Fernández Cortés y Cantos. en campo de gules, en el segundo y tercero. Las armas situadas a la diestra son las de los Barrionuevo (o Barnuevo); precisamente la bisabuela paterna de Andrés era Juana García de Barrionuevo, lo que justifica la presencia de aquéllas en este escudo de los Cantos. Más adelante, en otra escueta cláusula, el capitán dice: "Ytem quiero y es mi boluntad que el tal posehedor [del mayorazgo] tenga mi apellido de Cantos e armas de suso por mí declaradas" (Santamaría, 2002, p. 78).

El escudo descrito aparece en la fachada de la conocida como "casa Perona" en la calle de la Feria, aunque el animal en las garras del águila no es un conejo, como indica el capitán, sino un cordero (figura 12). Propiedad en el siglo XVIII de Juan Fernández Cortés y Cantos (Córcoles, 2010, p. 113) ${ }^{36}$. Juan Fernández Cortés (y Cantos) era hijo de Juan Fernández Cortés (1674-1734), regidor perpetuo, y de María de Cantos, que vivían en la calle de la Feria, nieto, a su vez de Juan Fernández Cantos (Cózar, 2010, pp. 272-276).

\section{LA POSADA DEL ROSARIO. DESCRIPCIÓN DEL INMUEBLE}

La descripción del edificio según Luis Guillermo García-Saúco es la siguiente:

La construcción es de planta cuadrada y se articula alrededor de un patio

${ }^{36}$ El expediente judicial para determinar la titularidad de un solar en la calle de la Feria en 1737 también nos proporciona datos que nos permiten ubicar la casa de don Juan Fernández Cantos. AHPAB. Signatura 348, 2. 
interior de idéntica estructura, con un sistema adintelado de columnas de cierto carácter jónico en el cuerpo inferior, mientras que en la planta superior toda la estructura, también adintelada, es enteramente de madera, conformando una hermosa galería cerrada que bordea el espacio interno. El acceso a las distintas estancias, tanto arriba como abajo, se realiza a través de variados arcos góticos, mixtilíneos, conopiales o escarzanos, labrados todos en yeso. La entrada original al edificio se sitúa en un extremo, casi en un ángulo, no en el eje, con un gran arco de medio punto de cantería de amplias dovelas que da paso al zaguán y de éste, en eje acodado, al patio interior, en un claro recurso de privacidad, como también las pequeñas ventanas, todo de estirpe y tradición musulmana. En conjunto, presenta una curiosa mezcla gótico-mudéjar-renacentista afortunadamente recuperada (2015, s.p). (Figura 13)
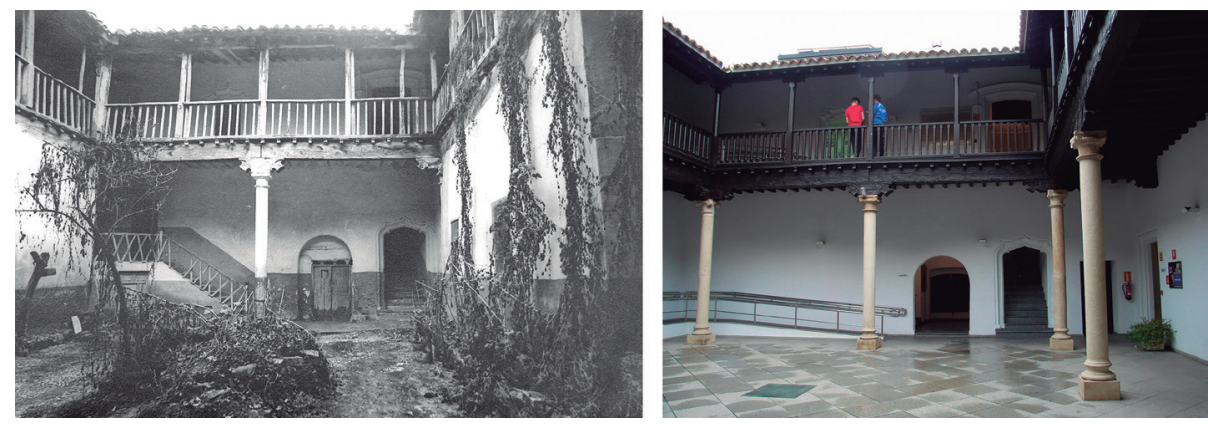

Figura 13. Imagen del patio de la posada antes y después de la restauración. Foto en blanco y negro de 1970: Segura. AHPAB. 75.788, 4.

Según el informe del arquitecto municipal realizado en 1979, el sistema constructivo era de tapial en los muros y basamentos, forjados de cuartones de madera y cubierta inclinada de teja árabe, sobre enlatado de madera y pares del mismo material. Se componía de dos plantas y sótano o cueva. En el bajo se hallaba un zaguán o patio y dependencias como comedor y dormitorio, más una cocina-chimenea apoyada en cuatro pechinas que parece haber sido construida en el siglo XVIII. En la planta alta se encontraban los dormitorios y galería ${ }^{37}$.

En origen la posada tenía una superficie mayor a la actual pues incluía corrales ya perdidos, su extensión era de $1.827 \mathrm{~m}^{2}$, frente a los $908 \mathrm{~m}^{2}$ actuales. Además de la huerta que llegó hasta el siglo XX cuando sus propietarios, los marqueses de Villores, la donaron al Ayuntamiento para que

${ }^{37}$ AMAB. S1-1384 I y AHPAB. Signatura 56.321, 4. 
se abriera la calle que, en agradecimiento a este gesto, lleva el nombre de marqués de Villores (Quijada, 1925, p. 88).

\subsection{La posada en el siglo XX}

Tras su cierre como hospedaje a mitad del siglo XX llegó la decadencia del inmueble. La falta de vigilancia - a pesar de ser uno de los pocos edificios con historia de la ciudad- provocó un rápido deterioro y consiguiente expolio. Su recuperación fue un ejemplo de implicación de toda la sociedad albacetense. Al parecer, las primeras gestiones las realizó don Joaquín Sánchez Jiménez, director del Museo. Desde 1963 Samuel de los Santos, que ocupó el mismo puesto, inició el expedien-

te de declaración de monumento.

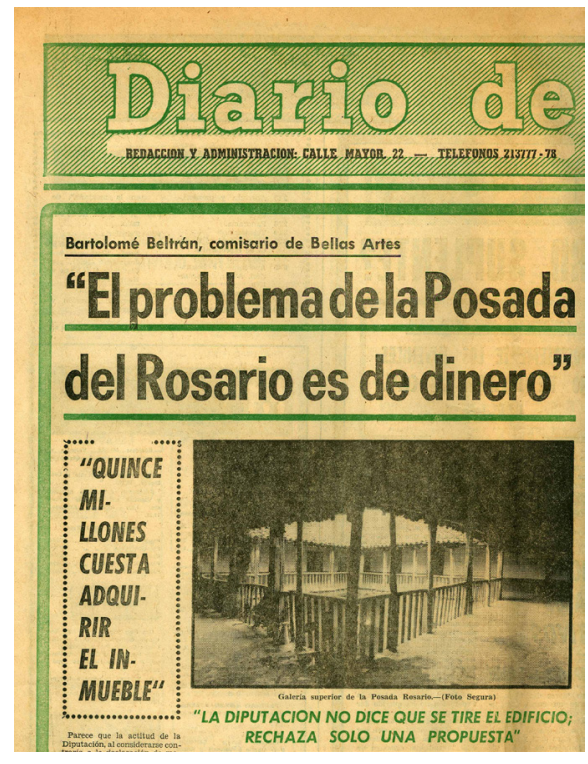

Figura 14. 18-abril-1974. Diario de Albacete. La Diputación rechazó la propuesta de monumento de carácter provincial debido a la limitación de medios financieros y técnicos para asumir las obligaciones y cargas que se derivaban de esta declaración. AHPAB. Signatura 75.788, 4 . En 1970 se hizo cargo de los trámites Bartolomé Beltrán, jefe de la sección de Bellas Artes de la Diputación, Para evitar su ruina a la posada se le intentaron crear diversos fines. Se ideó convertirla en un mesón típico e incluso instalar las oficinas de la Delegación de Vivienda. El principal obstáculo para conseguir su recuperación fueron los quince millones de pesetas (90.000 €) que los propietarios pedían por el inmueble, motivo por el que en 1973 la Diputación rechazó hacerse cargo de ella tras haberla declarado monumento histórico-artístico de carácter provincial la Dirección General de Bellas Artes a instancias del organismo provincial. Al parecer la institución no podía hacer frente a ese precio y su posterior restauración (figura 14).

Sin embargo, el interés y la polémica que despertó en la sociedad (informes, artículos de prensa, editoriales, cartas, unas decididamente a favor, otras en contra) consiguieron su rescate cuando ya pesaba sobre ella la declaración de ruina, decretada por la Comisión Permanente 
Municipal el 9 de marzo de 1978. El estado de la posada era lamentable: bombeados en los muros, desplomes y grietas eran los daños no reparables técnicamente por necesitar una reconstrucción total. A pesar de todo, la posada contaba con un inquilino que regentaba un pequeño comercio de comestibles en el bajo que se oponía al desalojo y a la demolición del inmueble solicitada por el dueño y denegada por el ayuntamiento y ratificada en la Audiencia Territorial en sentencia de 2 de julio de 1979, en tanto la Dirección General de Patrimonio Artístico no se pronunciara sobre la declaración de monumento histórico artístico de carácter nacional pendiente desde $1977 .^{38}$ Ésta se logró unos meses después, en 1980, por Real Decreto 808/1980 de 7 de marzo (BOE de 3 de mayo) ${ }^{39}$. El siguiente paso fue modificar las alineaciones contenidas en las Normas Subsidiarias de Planeamiento de 1981 para proteger el edificio, modificación que pasó al Plan General de 1985, donde se perfiló ya la calle peatonal alrededor de la Posada y los soportales (Magán, 1997, p. 208). El inmueble fue objeto de expropiación forzosa por el ayuntamiento en el año 1986. El justiprecio acordado con los dueños fue la permuta de un solar, propiedad municipal ubicado en la Avenida de España, n. $\stackrel{\circ}{4} 7^{40}$.

\subsection{El anexo de la portada de la casa de Los Picos}

Aprovechando la restauración del edificio en el año 1994 se incorporó en un lateral una puerta de acceso a las salas de estudio (figura 15). Se trata de la portada principal de la llamada "Casa de los Picos" (siglos XVI-XVIII) que formaba parte de la desaparecida casa-palacio de los condes de Villaleal en la calle de Gaona desmontada hacia 1977 (García-Saúco, 1991, p. 191) (figura 16), y reubicada antes de llegar a este emplazamiento en la plaza del barrio de las Seiscientas (Mateos, 1983, p. 174). Lo más característico de la fachada-retablo son:

Los picos-puntas de diamante que cubren todo el paño y los escudos rodeados de laureas, todo dentro de una línea renacentista, y por último unas molduras en el acceso más barrocas. El enmarcamiento del vano adintelado de acceso con pilastras cajeadas y molduras en orejeras advierten de una intervención dieciochesca. En el interior tenía un patio con columnas corintias que sostenían dinteles de madera. (García-Saúco, 1991, p. 191, 2006, p. 69).

\footnotetext{
${ }_{38}$ 1978-80. Expediente contencioso-administrativo sobre denegación de licencia municipal de demolición del edificio conocido como "posada del Rosario". Audiencia Territorial de Albacete. AHPAB. Signatura 56.321, 4.

${ }^{39}$ AHPAB. Signatura 75.788.

${ }^{40}$ AMAB. Signatura 3.961.
} 


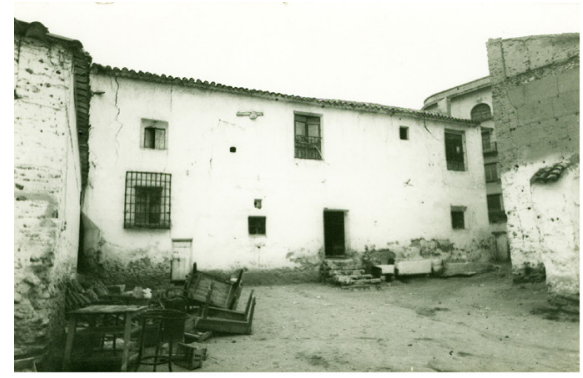

Figura 15. Vista posterior de la salida a los corrales en la antigua posada. A la derecha, portada de los Picos instalada en el mismo lugar que sirve de acceso a la sala de lectura. Foto en blanco y negro: Segura. AHPAB. $75.788,4$.

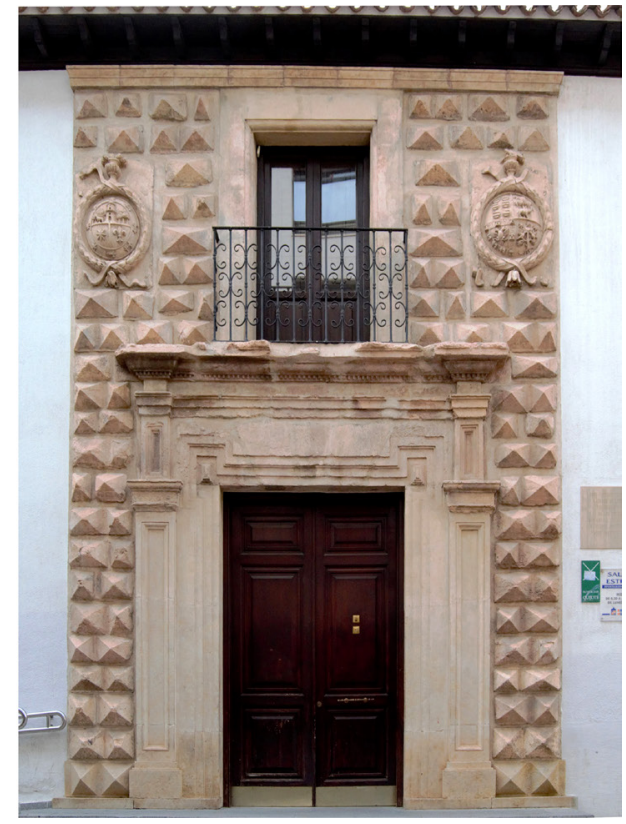

El inmueble tenía una superficie de $1.608 \mathrm{~m}^{2}$ según el registro de edificios de la riqueza urbana de 1881, fecha en que estaba habitada por cuatro inquilinos ${ }^{41}$. Era la de mayor valor económico de toda la calle según los padrones de la riqueza urbana. Su propietario fue de don Fernando Carrasco Rocamora, Oca, Gaitán, Suárez de Toledo, Castro, Cobos, Bernal, Molins, Piquinoti, Siaño y Loyola, alférez mayor de Albacete, $V$ conde de Villaleal, maestrante de la Real de Valencia, señor de Molins y Pozo Rubio ${ }^{42}$.

Como corresponde a una familia tan acaudalada las casas familiares fueron varias: en 1765, don Antonio Carrasco y Castro, padre de don Fernando, vivía en la calle de la Feria ${ }^{43}$. Un documento notarial fechado el día 30 de junio de 1787, nos informa de otra propiedad, el interviniente es don Fernando, quien renunció en favor de su hermano Manuel, a un mayorazgo que fundaron don Pedro Carrasco y su mujer,

${ }^{41}$ AHPAB. Signatura 34.544. Casa en calle Gaona n.ำ 12. Dos plantas, sótano en la primera crujía. En el Registro de edificios y solares de Hacienda de 1907 aparece con $1.858 \mathrm{~m}^{2}$. ${ }^{42}$ AHPAB. Signatura 1.032. 28/05/1793. Filiación completa de don Fernando en un poder notarial para reclamar el mayorazgo de Oca.

${ }^{43}$ Relación de casas de primera categoría para alojar el séquito de la Infanta a su paso por Albacete. AHPAB. Signatura 322. 


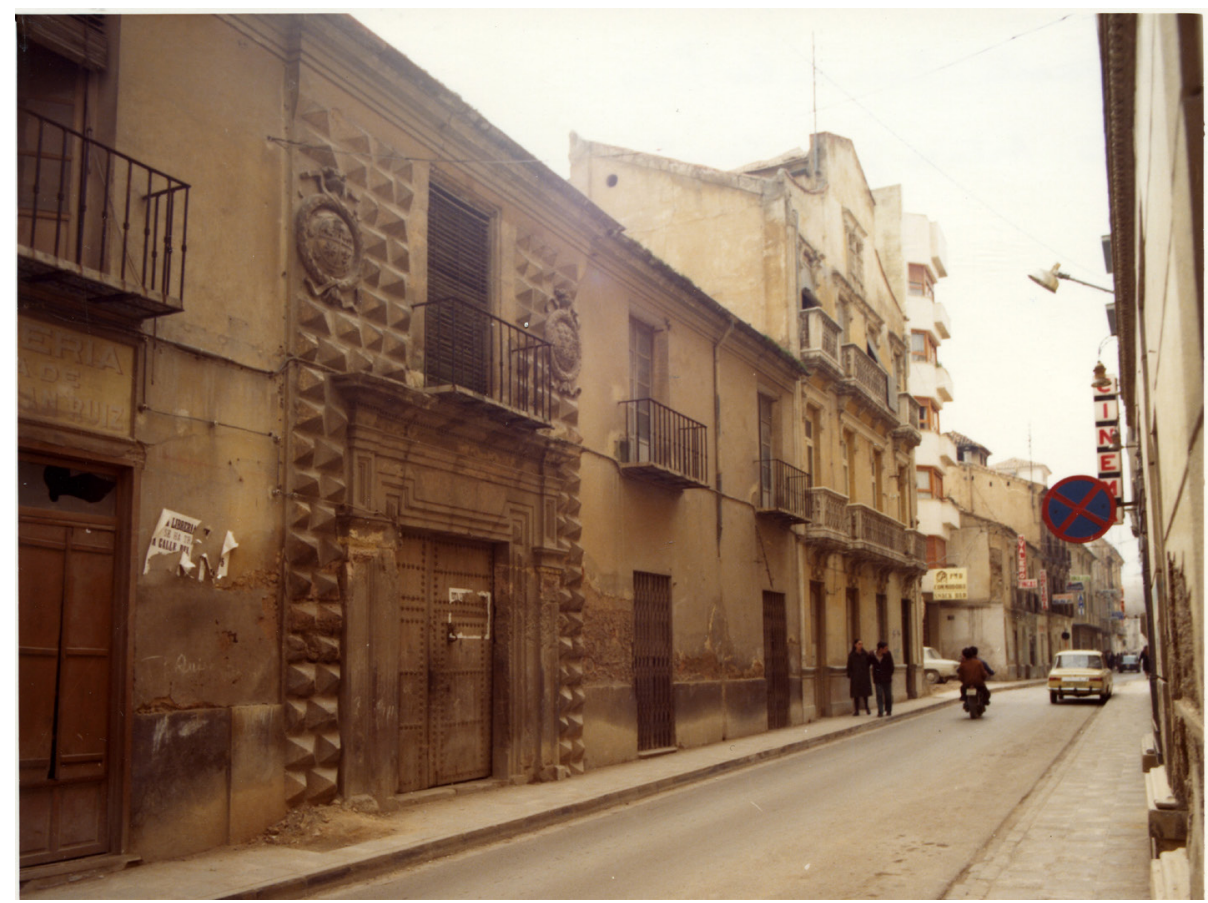

Figura 16. Original emplazamiento de la casa de los Picos en la calle Gaona. El edificio fue demolido en 1977 pero se conservó la fachada que hoy en día se halla en un lateral de la posada del Rosario. Fondo IEA. Autor: Arturo Gotor.

doña María Carrasco, que incluía, entre otros bienes, una casa principal en el barrio Cebrián o calle del doctor Marcilla (plaza Mayor) donde vivía su madre, doña Eustaquia Rocamora ${ }^{44}$.

Sabemos con toda certeza que don Fernando residió en otra de sus casas mucho mejor situada, la del Altozano, adquirida por don Juan Carrasco de Oca Gaitán en 1712 a otros parientes (Córcoles, 2005, p. 15). Corría el año de 1802 cuando en este inmueble se alojó el rey Carlos

\footnotetext{
${ }^{44}$ El protocolo notarial de 1787 se encuentra en la signatura 1.031 del AHPAB. La calle del doctor Marcilla y Villacerrada se consideran una unidad en los padrones del siglo XVIII en los que aparece doña Eustaquia Rocamora. A pesar de la indefinición de la topografía en los padrones, cuyo fin es la recaudación fiscal pero no el control de la población, creemos que se trata de la plaza Mayor. A través de estos documentos vemos como la calle del doctor Marcilla y la Villacerrada aparecen unidas hasta 1795 en que se segregan y aparece la calle Mayor unida a la calle Zapateros, ésta última ya se registraba siglos atrás. Se unen, por tanto, Zapateros y Mayor, quedando sola Villacerrada. Esto significa que doctor Marcilla englobaba la plaza Mayor, que ahora ha pasado a incluirse en la calle Mayor.
} 
IV en su visita a la villa ${ }^{45}$. Cuenta Sánchez Torres, que su gestión como político fue casi redentora para la villa de Albacete, ya que, debido a las epidemias de paludismo y anegación de cosechas por las aguas estancadas, la población tendía a desaparecer, y así, aprovechando la visita del rey Carlos IV a Albacete, expuso el conde la dramática situación al monarca quien comprendió e impulsó la construcción del Real Canal de María Cristina, base de la futura prosperidad de esta población (1916, p. 29).

Don Fernando murió en 1807, su única hija heredó sus bienes, entre ellos la casa de la calle Gaona, de la que aparece como propietaria doña Francisca Carrasco, VI condesa de Villaleal, en el padrón fiscal de 1812, dato que se repite en los de 1834 y 1848. La posesión pasó después a uno de sus hijos, don Juan Roca de Togores y Carrasco, senador por la provincia de Albacete en 1876, en cuyo expediente político aparecen varias certificaciones de todos sus bienes, que incluyen esta casa en el número 12 de la calle Gaona y otras más, una de ellas en el Altozano, la casa principal. En el siglo XX, fue comprada por José y Antonio Gómez Alfaro el 2 de junio de 1914. El 23 de enero de 1943 figuraba como herencia de Dolores Joaquina Ruiz Martít ${ }^{46}$.

\subsection{Los escudos de armas de la fachada}

Los escudos que flanquean su portada corresponden a esta familia hidalga de rancia tradición en Albacete. Su descripción y origen nos son descritos en el expediente tramitado a don Fernando Carrasco como solicitante de la orden de Carlos III ${ }^{47}$. Fernando Carrasco y Rocamora (17541807) casó con María Joaquina de Arce y Lara, natural de La Roda, él era hijo de don Antonio Carrasco de Oca y Castro, natural de la ciudad de Murcia y de doña Eustaquia Rocamora y Piquinoti, natural de Orihuela.

El título de conde de Villaleal lo heredó de su familia materna. Su madre, doña Eustaquia Rocamora y Piquinoti, nacida en Orihuela el 3

\footnotetext{
${ }^{45}$ AHPAB. Signatura 322. 1802-1805. Expediente sobre la visita de Carlos IV.

${ }^{46}$ Registro fiscal de edificios y solares. AHPAB. Carpeta 74.488. Padrones de 1812, Signatura 204, 1. Padrón de riqueza urbana de 1834, Signatura 204, 4. Estadística de la riqueza territorial de 1848 en 298. El expediente personal en archivo del senado: http://www.senado.es/web/conocersenado/senadohistoria/informaciongeneral/index.html [consulta 14/12/2019].

${ }^{47}$ AHN ESTADO-CARLOS_III, Exp.976. Digitalizado y accesible en http://pares. mcu.es. [consulta 14/12/2019].
} 
de noviembre de 1735, era hija de don Eustaquio Rocamora y Ruiz y de doña Luisa Piquinoti, nieta por línea materna de don José Joaquín Galindo Piquinoti, hijo del primer conde de Villaleal, don Benito Galindo Piquinoti, uno de los banqueros regios ennoblecidos por Felipe IV, a quien le otorgó el título creado el 23 de enero de 1675 (Felices, 2013, p. 430).

Fernando Carrasco consiguió la orden de Carlos III por decreto de 22 de noviembre de 1795, otorgándosele al mismo tiempo la facultad para usar las armas de sus antepasados "en escudos, casas o capillas y obras, sepulturas y en las otras partes que quisiere y que son las de los Carrascos y Villanuevas", obtenidas por primera vez por los hermanos don Pablo y don Pedro, que consiguieron ejecutoria de hidalguía "firmada por su majestad y refrendada por Juan Escobedo, su secretario, su fecha en Madrid a nueve de noviembre de 1564". La descripción de las armas es la siguiente: ${ }^{48}$

Un escudo de tres cuarteles, del medio arriba un castillo y asido a él un lebrel y seis carrascas en cada lado del castillo tres todo en campo dorado con pintas verdes y en los dos cuarteles de abajo en el de la mano derecha una estrella de oro en campo azul y en el de la mano izquierda una flor de lis en campo plateado y por orla de dicho escudo cuatro estrellas en campo azul a la mano derecha y a la mano izquierda cuatro flores de lis en campo colorado y por timbre e divisa del dicho escudo un yelmo plateado esmaltado de negro abierto con follaje verde y azul en el yelmo y arredonda de dicho escudo como aquí en esta mi carta van pintados.

Aunque se anota, no se llegó a dibujar, pero la descripción coincide con la réplica en piedra, salvo en los elementos externos como el yelmo sustituido por un dieciochesco florero, y el follaje, que en este caso lo ocupa la corona laureada (figura 17). Elementos ambos típicamente neoclásicos que corroboran la intervención en la fachada en el siglo XVIII que ya citaba Luis Guillermo García-Saúco.

Las armas de los Carrasco, como linaje principal, están situadas a la derecha de la portada, pero entendiendo por esta la que corresponde a la derecha del cuerpo del guerrero, como si lo portara. Por ello, visto de frente para nosotros se sitúa a la izquierda. La misma lectura se debe observar en los escudos. Por deducción, las del otro lado corresponden al resto de los linajes con los que entroncó el titular, bien

${ }_{48}$ AHN ESTADO-CARLOS_III, Exp.976. Digitalizado y accesible en http://pares. mcu.es. 


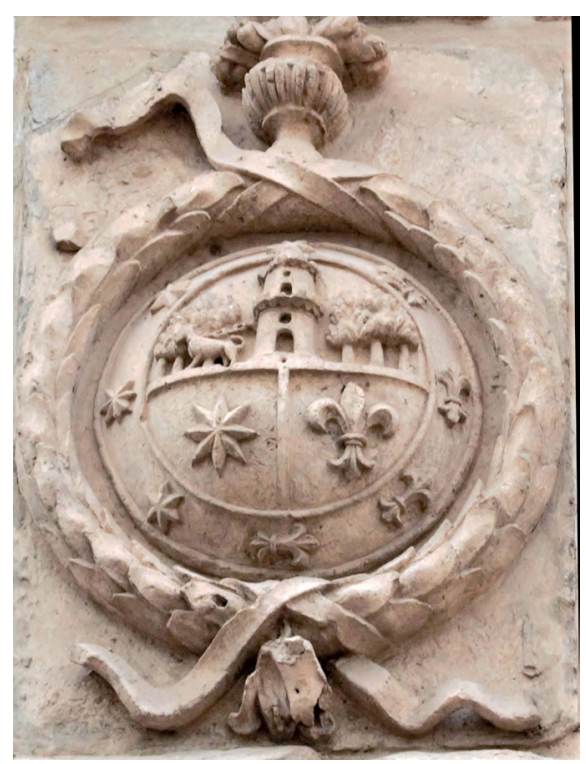

Figura 17. Armas del linaje principal. Escudo redondo cortado y medio partido de los Carrasco y los Villanueva. Portada de acceso a la sala de estudio en la posada del Rosario.

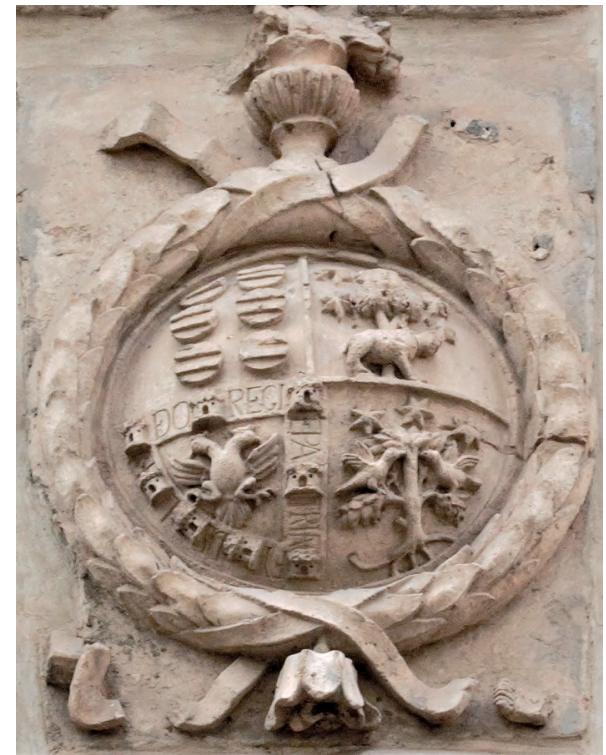

Figura 18. Escudo redondo cuartelado a la izquierda de la portada de acceso a la sala de lectura de la posada del Rosario.

directamente o bien de forma colateral tras agotarse las vías de sucesión directa en el caso de algunos mayorazgos (figura 18).

El primer cuartel no lo hemos identificado, pero se compone de seis bezantes en dos palos de a tres cargados de fajas gemelas, que guarda similitud con el linaje Castro, apellido perteneciente a sus ascendientes. El segundo, creemos que proviene del mayorazgo heredado del bisabuelo, don Pablo Carrasco de Oca, nacido el 23 de noviembre de 1634, obtuvo en 1650 el hábito de Santiago, en el expediente se detalla la genealogía, la abuela paterna fue Brianda de Oca Zúñiga y Sarmiento, natural de la villa de Celme, obispado de Orense en Galicia. Ella era hija de don Diego de Oca Sarmiento y Zúñiga, señor de Celme, corregidor de Albacete $^{49}$. El mayorazgo de Celme fue creado en 1529 por don Álvaro de Oca y doña María Sarmiento. Con el tiempo, acabaría por ser reclamado por don Fernando en 1796 (Córcoles, Meya, 2005, p. 122). La descripción escrita en el Libro de Oro, manuscrito del archivo de don

${ }^{49}$ AHN. OM-CABALLEROS_SANTIAGO, Exp.1598. Digitalizado en https://www.familysearch.org/search/catalog/630488 [consulta 25/12/2019]. 
Alejandro Pedrosa Neira, es: en color de azur, un árbol de sinople sobre un terrasado de lo mismo y sobre éste, y pasante al pie del tronco, un lebrel siniestrado, de su color; un sol de oro en jefe y dos estrellas de oro de siete puntas en los cantones del jefe. Bordura de oro ${ }^{50}$ (figura 18). Por último, el tercer cuartel: águila bicéfala bicoronada, con bordura cargada de ocho castillos y lema: "Deo regi e patria". El escudo proviene de los San Clemente, que pertenecían a los Chancilleres, uno de los doce linajes fundadores de Soria, con los que entroncaba don Fernando Carrasco a través de don Pedro González Galindo y Orihuela. La genealogía está inserta en el manuscrito 3251 de la Biblioteca Nacional de España (de la Rosa, p. 2015). En origen las armas se componían de un águila de sable y orla de sangre con ocho castillos de oro y el lema "fidele deo regi e patria" (fiel a Dios, al rey y a la patria) ${ }^{51}$. Cuarto cuartel: rosal arrancado cargado de rosas, con dos pájaros enfrentados en sus ramas, surmontado de tres estrellas de seis puntas, que se identifica con el que en algunos armoriales se asigna a los Rosell (Valero de Bernabé, 2004, p. 279). Estos entroncaban con la familia a través de doña Isabel Rocamora y su segundo marido, Don José Rosell, fundadores de un vínculo en 1662, que fue reclamado por doña Eustaquia Rocamora, madre de don Fernando, y cuya posesión no estuvo exenta de polémica y pleitos (Córcoles, Meya, 2005, pp. 117-118).

La hija de don Fernando, doña Francisca Carrasco y Arce, condesa de Villaleal, contrajo matrimonio con don Luis Roca de Togores y Valcárcel, natural de Orihuela, II conde de Pinohermoso, Grande de España, conocido por haber sido el alcalde de Albacete que obligó a Fernan-

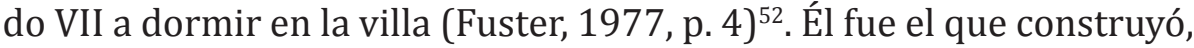
o más bien, reformó la casa palacio en el Altozano. El edificio llamó la atención de un viajero francés, Laborde, que en el año 1809 publicó la primera edición, en francés, de una obra titulada Itinerario Descriptivo de las provincias de España, y de sus islas. En el libro comenta que Al-

\footnotetext{
${ }^{50}$ Las estrellas en el escudo de la fachada que nos ocupa son de seis puntas, se trata de la única diferencia. En https://www.heraldicadeapellidos.com/index.php/ escudos [consulta 25/12/2019]. "Véase también el escudo n. 2.338 del Museo Arqueológico de Pontevedra; con los de Ulloa, Lis, Araujo, Roldán y asimismo Castro, procedente de la Casa de Sangro, antiguamente de Peire Roldán".

${ }^{51}$ Historia del palacio, linaje y escudo del siglo XVIII en el palacio del vizconde de Eza, en Soria. https://guiadesoria.es/soria-y-provincia/soria-ciudad/626-palacio-del-vizconde-de-eza.html [consulta 28/01/2019].

${ }^{52}$ El condado había sido creado en 1790 a favor de Juan Nepamuceno Roca de Togores y Scorcia, natural de Orihuela (Cadenas, 1987, p. 574).
} 
bacete tiene una iglesia parroquial, cinco conventos, un hospital y su población llega a 8.000 habitantes. Sobre la arquitectura de la villa resalta lo siguiente: "algunas de sus casas tienen hermosas decoraciones y fachadas y el palacio que está construyendo el conde de Pinohermoso es elegante" (131). El edificio que conocemos por fotografías antiguas aparecidas en el libro de Alberto Mateos respondía a un esquema burgués de clásica factura, sobria y simétrica fachada con piedra de sillería, entrada adintelada con columnas jónicas y grandes vanos en ventanas y balcones que proporcionaría luminosidad a las estancias (figura 19). Casa fuerte y grande en una plaza, visibilidad y dominio sobre el espacio, diferenciación con el resto del entramado urbano, aún muy anclado en la estructura rural. Tenía una superficie de $4.296 \mathrm{~m}^{2}$ en dos plantas, el bajo contaba con varias dependencias a que se destinaba la finca, cuadras, sótano, noria y descubierto, la planta superior con habitaciones, convenientemente distribuida ${ }^{53}$. Contaba con numerosos criados que reflejaban el poder e incrementaban el prestigio del dueño, así, en el padrón de carruajes y criados de 1812 se enumeran un coche, un cabriolé, un ayudante de cocina, un cocinero, un cochero, un ayuda de cámara, dos lacayos y un mozo de caballos. Por el contrario, su esposa que vivía temporalmente separada de él en la calle de la Feria declaraba escuetamente dos criados ${ }^{54}$.

Atrás quedaba la casona solariega de don Fernando Carrasco en la calle Gaona con los escudos de sus antepasados. La nueva generación con su yerno a la cabeza, don Luis Roca de Togores, político liberal, alcalde constitucional, tenía otras necesidades más acordes con su prestigio y su ideario. Además, la casa del Altozano gozaba de un inmenso solar y una mejor ubicación, no en vano esta plaza siempre contó con casas principales, además de servir de espacio lúdico y religioso para los eventos que no tenían cabida en la limitada plaza Mayor. La casa del conde de Pinohermoso fue la mejor en su momento, sus estancias acogieron a personas regias e ilustres, incluso las reuniones del ayuntamiento se celebraban en casa de don Luis (Córcoles, Meya, 2005, p. 17).

\footnotetext{
${ }^{53}$ AHPAB. Signatura 34.545. Registro de edificios de la contribución urbana, año 1882 para el registro de esta finca. Lindaba con las oficinas de la Hacienda Pública y solar del convento de Justinianas por la derecha conforme se entra, a la izquierda, la calle del Val y espalda con la calle Concepción y casa de don Luis García y Josefa la Fuente.

${ }^{54}$ AHPAB. Signatura 540, expediente 1.
} 


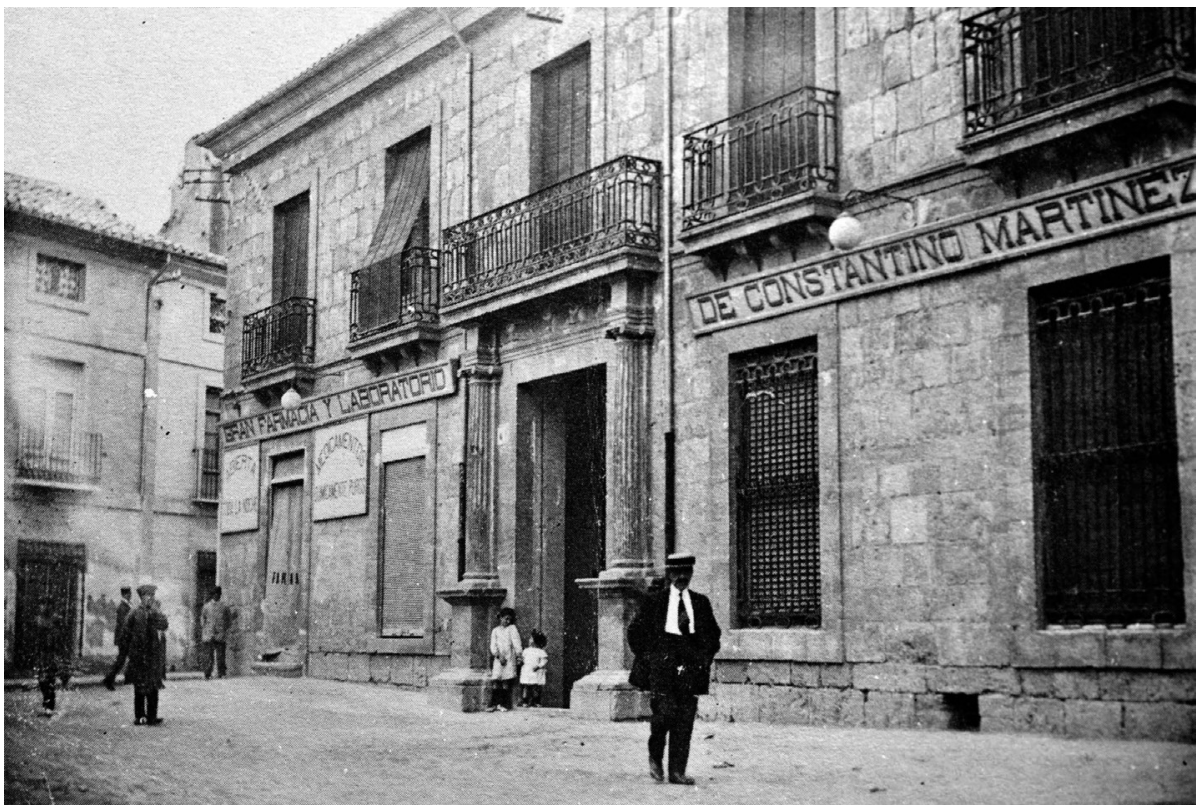

Figura 19. Casa del conde de Pinohermoso en el Altozano. Imagen anterior al año 1915. Del Albacete Antiguo. Alberto Mateos, p. 37.

\section{CONCLUSIÓN}

La vida de los hidalgos albacetenses que conocemos como hombres dedicados a la política (regidores, alcaldes y alféreces), a la carrera militar o a la actividad jurídica en el concejo de Albacete cobra nueva dimensión al descubrir sus casas y escudos como signos de identidad y proyección social del linaje. La identificación de sus armas nos ha llevado a la genealogía y esta nos ha permitido conocer quiénes eran los hidalgos que exhibían sus armas en casas y capillas, sus nombres y apellidos, su familia, su trayectoria vital y la función que cumplían las armas heráldicas, tanto en la formación del linaje, como en la promoción y representación social. La heráldica nos ha permitido identificar familias y datar las casas de sus poseedores. Casas que mantuvieron la memoria de presentes y antepasados inmortalizados en las armas que se exhibían en las puertas. La persona era conocida no individualmente sino en el conjunto familiar, como miembro de una cadena de la que se heredaba hacienda, honor y prestigio. "Nobleza es hidalguía que viene a los hombres por linaje” decía en las Partidas el Rey Sabio, y así parece que lo entendieron todos estos hidalgos que hemos rescatado gracias a 
sus expedientes de órdenes militares, nobiliarios, de ingreso en instituciones elitistas... herederos de vínculos y mayorazgos que se remontan a la Edad Media.

Con el tiempo, muchos factores contribuyeron a la depreciación de los inmuebles donde se exhibían blasones y arquitectura, el paso del Antiguo Régimen al Estado Liberal, el alejamiento de los herederos de la villa de origen, que preferían las oportunidades que brindaban las grandes ciudades con el consiguiente abandono de las casas. Desvinculación emocional y olvido de los signos, de la historia vivida por los antepasados y de su imbricación con Albacete. De esta forma se produjo la venta o cesión de auténticas "casas principales" o palacetes que desaparecieron de la urbe cuando parece ser que ya no significaban nada para nadie. Creemos que el conocimiento es fundamental para valorar el bagaje cultural que aún persiste. Quizá si no se hubiese perdido la identidad, la memoria y la historia que cargaban estos edificios, no hubiesen desaparecido. Es difícil evaluarlo, pero, en cualquier caso, rescatar el pasado nos proporciona argumentos para proteger y reivindicar el escaso patrimonio que subsiste en la ciudad. 


\section{REFERENCIAS BIBLIOGRÁFICAS}

ATIENZA, J. de (1959). Nobiliario español. Diccionario heráldico de apellidos españoles y de títulos nobiliarios. Madrid: Aguilar.

BARREDA Y ACEDO-RICO, J. de la (2011). Viejos linajes del Noroeste de Murcia. Madrid: Imprenta Taravilla.

CADENAS Y LÓPEZ, A. A. de, ATIENZA, J. de y CADENAS Y VICENT, V de (1987). Elenco de grandezas y títulos nobiliarios españoles. Madrid: Hidalguía.

CADENAS Y VICENT, V. de (1999). Heráldica patronímica española y sus patronímicos compuestos. Ensayo heráldico de apellidos originados en los nombres. Madrid: Hidalguía.

CADENAS Y VICENT, V. de (1993). Heráldica, genealogía y nobleza en los editoriales de "Hidalguía" (1953-1993). Madrid: Hidalguía.

CÁRDENAS, P. F., padre (1650). Varios apellidos y armas legalmente sacados de un Nobiliario que para en el Archivo del Real Convento de S. Pablo de Córdoba [Manuscrito]. Biblioteca Nacional en enhttp://bdh.bne.es/bnesearch/detalle/bdh0000119118 [consulta 30/12/2019]

CÓRCOLES JIMÉNEZ, P. y MEYA IÑÍGUEZ, M. (2005). Los señores de Pozo Rubio en la transición del Antiguo Régimen al estado liberal. Mantenimiento y consolidación de un linaje. Albacete: Instituto de Estudios Albacetenses.

CÓRCOLES JIMÉNEZ, P. y MEYA IÑÍGUEZ, M. (2002). El señorío de Pozo Rubio (siglos XVI a XVIII) aproximación a una familia ilustre de Albacete: los Carrasco. De la milicia a las letras. En A. SANTAMARÍA CONDE; L. G. GARCÍA-SAÚCO BELÉNDEZ y J. SÁNCHEZ FERRER, (Coords.). II Congreso de Historia de Albacete. III Edad Moderna. (pp. 189-207). Albacete: Instituto de Estudios Albacetenses.

CÓRCOLES JIMÉNEZ, P. (2010). La calle de la Feria en la primera mitad del siglo XVII. Noticias sobre sus edificaciones y habitantes ilustres. En AA.VV. La Feria de Albacete en el tiempo. Aspectos sociales, culturales y económicos. (pp. 108-115) Albacete: Pubalsa.

CÓZAR GUTIÉRREZ, R. (2010). Albacete, corregimiento borbónico. Madrid: Silex.

FELICES DE LA FUENTE, M. del M. (2013). Recompensar servicios con honores: el crecimiento de la nobleza titulada en los reinados de Felipe IV y Carlos II. En Stud. His., His. Maㅡ, (35), pp. 409-435. Recupe- 
rado en: DOI: http://dx.doi.org/10.14201/shhmo201335409435. FUSTER RUIZ, F. (1977). El alcalde que obligó a Fernando VII a dormir en Albacete (1814). Al-Basit, (4), pp. 4-22. Albacete: Instituto de Estudios Albacetenses. http://iealbacetenses.dipualba.es/pdf.raw?query $=$ id:0000041613\&page $=5 \&$ lang $=$ fr $\& v i e w=$ press. [consulta 14/12/2019].

GARCÍA CARRAFFA, A. y A. (1920). Enciclopedia heráldica y genealógica hispano-americana. Tomo V. Madrid.

GARCÍA-SAÚCO BELÉNDEZ, L. G. (1982). Albacete, 600 años. (Coord). Albacete: Museo de Albacete.

GARCÍA-SAÚCO BELÉNDEZ, L. G. (1991). Desarrollo urbanístico de Albacete, En AA.VV. Albacete en su Historia. Albacete: Ayuntamiento.

GARCÍA-SAÚCO BELÉNDEZ, L. G. (2006). Apuntes para una historia del Arte de Albacete. Albacete: La siesta del lobo.

GARCÍA-SAÚCO BELÉNDEZ, L. G. (2015). Albacete por dentro. Un proyecto para conocer la ciudad... a pie. Albacete: Instituto de Estudios Albacetenses.

GARCÍA-SAÚCO BELÉNDEZ, L. G., SÁNCHEZ FERRER, J., SANTAMARÍA CONDE A. (1999). Arquitectura de la provincia de Albacete. Toledo: Junta de Comunidades de Castilla La Mancha.

GÓMEZ CARRASCO, C. (2007). Entre el mundo rural y el mundo urbano. Albacete: Instituto de Estudios Albacetenses.

GONZÁLEZ-VARAS IBÁÑEZ, I. (2018). Palacios y casas señoriales de España: un recorrido a través de su historia y de sus propietarios. Madrid: Turner.

GUARDIOLA, J. B. (1591). Tratado de nobleza, y de los títulos ditados que oy día tienen los varones claros y grandes de España. Madrid: impresor Ruiz, María.

LABORDE, A. de (1816). Itinerario descriptivo de las provincias de España. (Traducción libre del publicado por A. Laborde en 1809). Valencia: imprenta de Ildefonso Mompié.

MAGÁN PERALES, J. M. (1997). El desarrollo urbanístico de la ciudad de Albacete. Albacete: Instituto de Estudios Albacetenses.

MARICHALAR, A. (1941). Una incorporación a Navarra (Los San Clemente). En Príncipe de Viana, (año II. 3), págs. 70-77. [Es separata de la revista] https://dialnet.unirioja.es/servlet/articulo?codigo=2235732. [consulta 23/01/2020].

MATEOS ARCÁNGEL, A. (1983). Del Albacete antiguo (imágenes y re- 
cuerdos). Albacete: Instituto de Estudios Albacetenses.

MENÉNDEZ-PIDAL DE NAVASCUÉS, F. (2006). El linaje y sus signos de identidad. En LADERO QUESADA, M. A. (coord.). Estudios de genealogía, heráldica y nobiliaria. Madrid: Universidad Complutense.

MENÉNDEZ-PIDAL DE NAVASCUÉS, F. (2015): La nobleza en España: ideas, estructuras, historia. Madrid: Real Academia de la Historia-BOE.

MOGROBEJO, Endika, Irantzu y Garikoitz de (2003). Diccionario hispanoamericano de heráldica, onomástica y genealogía. Bilbao: Editorial Mogrobejo-Zabala.

QUIJADA VALDIVIESO, J. (1925). Albacete en el siglo XX. Albacete: tipografía de Eliseo Ruiz.

ROSA FERRER, I. de la: "Los Origüela de San Clemente: Astudillos y Piquinotis" En Historia del corregimiento de San Clemente. https:// www.academia.edu/20361548/Los_Orig\%C3\%BCela_de_San_ Clemente [consulta 25/12/2019].

ROSA FERRER, I. de la. "Linajes de San Clemente: Origüela, Valenzuela, Araque, Oma, Granero, Garnica y de la Fuente". En Historia del corregimiento de San Clemente. https://www.academia. edu/20361548/Los_Orig\%C3\%BCela_de_San_Clemente [consulta $25 / 12 / 2019]$.

SÁNCHEZ TORRES, F. J. (1916). Apuntes de historia de Albacete. Albacete: Imprenta Eliseo Ruiz.

SANTAMARÍA CONDE, A. (2002). Acerca del capitán Andrés de Cantos (siglo XVI). En A. SANTAMARÍA CONDE; Luis G. GARCÍA-SAÚCO BELÉNDEZ y J. SÁNCHEZ FERRER, (Coords.) II Congreso de Historia de Albacete. III Edad Moderna. (pp. 75-91). Albacete: Instituto de Estudios Albacetenses.

VALERO DE BERNABÉ Y MARTÍN DE EUGENIO, L. (2004). La Fitoheráldica: las Figuras Vegetales en la Heráldica Española. Sevilla: Fabiola de Publicaciones Hispalenses.

VALERO DE BERNABÉ Y MARTÍN DE EUGENIO, L. (2007): Análisis de las características generales de la heráldica gentilicia española y de las singularidades heráldicas existentes entre los diversos territorios históricos hispanos. (Tesis doctoral). Madrid: Universidad Complutense. Recuperado en: https://eprints.ucm.es/7764/ 
